\title{
APROXIMACIÓN AL PATRIMONIO ARQUEOLÓGICO SUBACUÁTICO DE SAN FERNANDO (CÁDIZ). UN EXTRAORDINARIO LEGADO EN TORNO AL ISLOTE DE SANCTI-PETRI
}

\author{
AN APPROACH TO THE UNDERWATER ARCHAEOLOGICAL HERITAGE IN SAN FERNANDO (CÁDIZ). \\ AN EXTRAORDINARY LEGACY AROUND SANCTI-PETRI ISLET
}

\section{Aurora HIGUERAS-MILENA CASTELLANO}

IAPH - Centro de Arqueología Subacuática, Balneario de la Palma, Duque de Nájera 2, 11004, Cádiz

Resumen: Partiendo de la descripción del medio físico, realizaremos una aproximación al Patrimonio Cultural Subacuático (PAS) del entorno de San Fernando, abarcando los tres frentes que rodean la antigua isla: a) el caño de Sancti Petri, con el mayor número de hallazgos de época antigua y donde se presume la existencia de importantes yacimientos b) la recta playa abierta al Océano, que conserva en sus aguas importantes pecios que superaron batallas pero que fueron vencidos por temporales, y c) la Bahía interior, que atesora las huellas de la continuada ocupación y tránsito. Haremos un recorrido rápido por los principales yacimientos arqueológicos de la zona, incluidos en la Carta Arqueológica Subacuática, así como por las intervenciones que han permitido su localización y documentación, con una parada detenida en la historiografía de Sancti Petri. La sistematización de la documentación volcada en el artículo permitirá evidenciar el intenso devenir histórico del área de estudio y su extraordinario legado arqueológico.

Palabras Clave: Isla de León, San Fernando (Cádiz), Sancti Petri, geomorfología, paleopaisaje, marismas, naufragio, pecios, Centro de Arqueología Subacuática del Instituto Andaluz del Patrimonio Histórico.

\begin{abstract}
Starting from the description of the physical environment, we will make an approach to the underwater cultural heritage of the San Fernando environment, covering the three fronts that surround the old island: the straight beach open to the Ocean, which preserves in its waters important wrecks that overcame naval battles but not temporary, the Sancti Petri stream with the largest number of finds from ancient times but also with endless hypotheses, and the Inner Bay, which treasures the traces of the continued occupation. We intend a quick tour of the main archaeological sites included in the Underwater Archaeological Charter, as well as the interventions that have allowed their location and documentation, with a stop at the historiography of Sancti Petri.
\end{abstract}

Keywords: Isla de León, San Fernando (Cádiz), Sancti Petri, geomorphology, wetlands, shipwrecks, Centre for Underwater Archaeology of the Andalusian Institute of Historical Heritage.

Sumario: 1. Introducción. 2. Un patrimonio adaptado al medio. 2.1. El Caño de Sancti Petri y su desembocadura. 2.2. La recta playa al frente del océano. 2.3. Bahía interna. 2.4. Terrenos inundables. 3. De las primeras exploraciones a las actuaciones arqueológicas regladas. 3.1. Hallazgos fortuitos tras la bajamar. Noticias del siglo XVIII. 3.2. Hallazgos del siglo XIX. Paraje en el punto de mira. 3.3. Hallazgos y actuaciones del siglo XX hasta los 70. El ocaso de los emperadores. 3.4. Intervenciones y hallazgos desde los años 70 a la actualidad. 4. La Isla en la Carta Arqueológica Subacuática. Prevenir y Proteger: ¿Qué conocemos? 5. Conclusiones. Sobre los trabajos pendientes. 6. Bibliografía.

\section{Introducción}

La arqueología subacuática aborda el estudio de un patrimonio muy variado. Según el Anexo de la Convención de la UNESCO de 2001, en su artículo 1, por Patrimonio Cultural Subacuático "se entiende todos los rastros de existencia humana que tengan un carácter cultural, histórico o arqueológico, que hayan estado bajo el agua, parcial o totalmente, de forma periódica o continua, por lo menos durante 100 años, tales como: los sitios, estructuras, edificios, objetos y restos humanos, junto con su contexto ar- 
queológico y natural; los buques, aeronaves, otros medios de transporte o cualquier parte de ellos, su cargamento u otro contenido, junto con su contexto arqueológico y natural; y los objetos de carácter prehistórico".

Otras denominaciones para este patrimonio, como submarino, náutico, marítimo o naval pueden ser más concretas pero menos inclusivas. También se utilizan aquellas que diferencian de alguna manera el "ambiente" en el que se encuentra el yacimiento, como han señalado algunos autores al referirse en concreto a San Fernando, que emplean "arqueología litoral"(Bernal, 2005: 217), o "arqueología del medio acuático" (Blot, 2003: 27-28) término que consideran mas interdisciplinares, que no se limita solo a lo sumergido, si no que engloba cursos y cuerpos de agua en sí mismos, ambiente marinos y del interior continental, es decir, en un río, el cauce de agua y el valle que lo contiene; en el océano, la faja litoral adyacente (Prates y Bonomo, 2017: 14).

Optamos por la denominación Subacuático, término jurídico que se utiliza para la protección de este Patrimonio Cultural, concepto es muy amplio en cuanto a los bienes que se relacionan $e$ incluso incorpora el contexto arqueológico y natural de los mismos (Castillo, 2014: 6), ya que incluye testimonios antropogénicos tan variados como infraestructuras portuarias, pesqueras o de comunicación, fondeaderos, naufragios, objetos que se hundieron de forma accidental o deliberada, los que estuvieron en tierra y ahora se encuentran sumergidos así como los localizados actualmente en tierra debido a cambios en la línea de costa, asentamientos y necrópolis, en zonas intermareales o en aguas interiores, pantanos o ríos, además de elementos patrimoniales de interés etnológico, como los molinos mareales y paisajes salineros.

De igual forma se ha ido ampliando el espacio temporal a este Patrimonio, más o menos restrictivo según los países, 50, 60 o 75 años (Castillo, 2014: 1); en el caso de España sin restricción, para abarcar desde la prehistoria hasta época contemporánea (Martín, 2003: 33), incluyendo restos de menos de 100 años que pueden tener un interés patrimonial histórico-arqueológico.

En el Término Municipal de San Fernando, una antigua isla rodeada de playas, arrecifes, islotes, caños y zonas inundables, y lo que es más importante, una intensa ocupación humana desde la Prehistoria, podemos imaginar el importante patrimonio arqueológico subacuático - submarino, naval, litoral o del medio acuático - que guarda. Un frágil legado que debemos conocer y proteger.

Para describirlo tenemos que enumerar las diversas actividades desarrolladas por sus habitantes a lo largo de la historia, determinadas a su vez por las materias primas que este entorno ofrecía: el agua dulce, su abastecimiento y control; el mar y la fabricación de conservas; las marismas y la explotación de la sal; la arcilla y la industria alfarera; y para movilizar todos estos productos a través de canales marítimos y fluviales, una importante industria de construcción naval, elementos de control del territorio. Incluso, más allá de las actividades locales antes referidas, veremos que este entorno ha sido escenario de eventos históricos que han dejado su huella bajo las aguas.

\section{Un patrimonio adaptado al medio}

¿Quién sabe hasta donde se extendía la
tierra
dentro del mar por la banda de medio día,
y cuántos espacios de estas tierras ha-
brán sido mar,
particularmente en lo que ahora llaman
marismas? (Antonio Ponz, 1794).

Viviendo en la actual San Fernando, no apreciamos que hemos estado y seguimos estando condicionados por la tectónica (afloramientos plio-pleistocenos y convergencias submarinas), cambios climáticos, periodos interglaciares (transgresiones y regresiones), actividades sísmicas, así como otros agentes más visibles como son: las corrientes marinas y fluviales, oleaje, mareas, vientos, y sobre todo la antropización, que en conjunto, han ido modelando nuestro tramo costero. Incluso la luna nos afecta, ya que una conjunción de temporales de invierno con mareas vivas, puede hacer retroceder la línea de costa, desaparecer playas, sistemas dunares y todo lo que estos ocultan.

Desde hace años los estudios geoarqueológicos han mostrado su interés por la zona de la Bahía, y en concreto por el término isleño. No en vano, los XIX Encuentros de Historia y Arqueología de San Fernando en 2003 se centraron en la Geoarqueología e Historia de la Bahía de Cádiz, donde se presentó el Proyecto Antípolis, publicado en esta misma revista (Arteaga, 2003) por lo que remitimos a las numerosas publicaciones sobre proyectos geoarqueológicos (Gallardo et al., 2000; Gracia et al., 1995, 2003; Llave et al., 1999), Proyecto Costa 
(Arteaga et al., 1985; Schulz et al,. 2003) y continua actualmente esta tendencia enfocada al estudios de efectos erosivos de eventos de alta energía (Alonso et al., 2015; Gracia et al., 2006).

La tectónica configuró a partir de fallas, en los terrenos de la actual Bahía de Cádiz, un sistema deltaico que fue inundado hace unos 6.500 años, debido a las oscilaciones térmicas, como se recoge en las numerosas investigaciones sobre reconstrucciones de los niveles del mar en el Cuaternario y la evolución costera (Alonso et al., 1997, 2003, 2004, 2009; Benot et al., 1993; Dabrio et al., 2000; Domínguez-Bella, 2008; Gracia et al., 2003; entre otros muchos). El empuje sobre arcillas y yesos (materiales de hace unos 250 millones de años) habría originado pliegues en la corteza terrestre, en la roca ostionera, elevando el terreno del Cerro de los Mártires, hasta $35 \mathrm{~m}$ sobre el nivel del mar y $30 \mathrm{~m}$ en la zona de Torre Alta. Sucesivas subidas y bajadas del nivel del mar a lo largo del Holoceno, crearon con la dinámica marina y fluvial, flechas litorales, que como la de Sancti -Petri, cerraron espacios y generaron marismas que desde entonces nos rodean (Alonso et al., 2009: 18-21).

Si partimos de las tres islas principales de la Antigüedad, muchos han sido los aportes sedimentarios que las han soldado (Figura 1).

Pero todos los cambios no deben atribuirse solo a los factores anteriormente descritos. El término arqueopaisaje heredado (sensu Bruquetas, 2017: 51) nos parece apropiado para explicar esta influencia en la evolución de nuestro entorno, generado y alterado a partir de la antropización desde la antigüedad, que ha provocado la colmatación de las marismas a partir de la construcción de calzadas, caminos, cercas de madera, gavias, embarcaderos, muros o puentes. Incluso la construcción de defensas en momentos de conflictos bélicos, ha modificado el paisaje, anegando salinas, abriendo muros, compuertas, cortaduras y canales, cambiando la navegación de sus aguas interiores, de modo que no pudiera ser reconocible en los mapas que tenía el enemigo. Era una de las estrategias del Conde de Alburquerque, quien conocía bien esta:

\section{Capacidad de mutación que causaban las actividades humanas en el paisaje de la Bahía de Cádiz, del mismo modo que sus moradores eran conscientes desde anti- guo de las variaciones a las que los proce- sos naturales sometían periódicamente a su morfología. (Chías y Abad, 2011: 27).}

El análisis de la cartográfica histórica permite advertir estas modificaciones que han ido transformando y configurando el paisaje actual (Alonso et al., 2011; Gómez et al., 2019; Meneanteau, 2008), para:

Reconstruir, no sólo la evolución morfológica de la parte emergida y sumergida de este marco geográfico, sino también
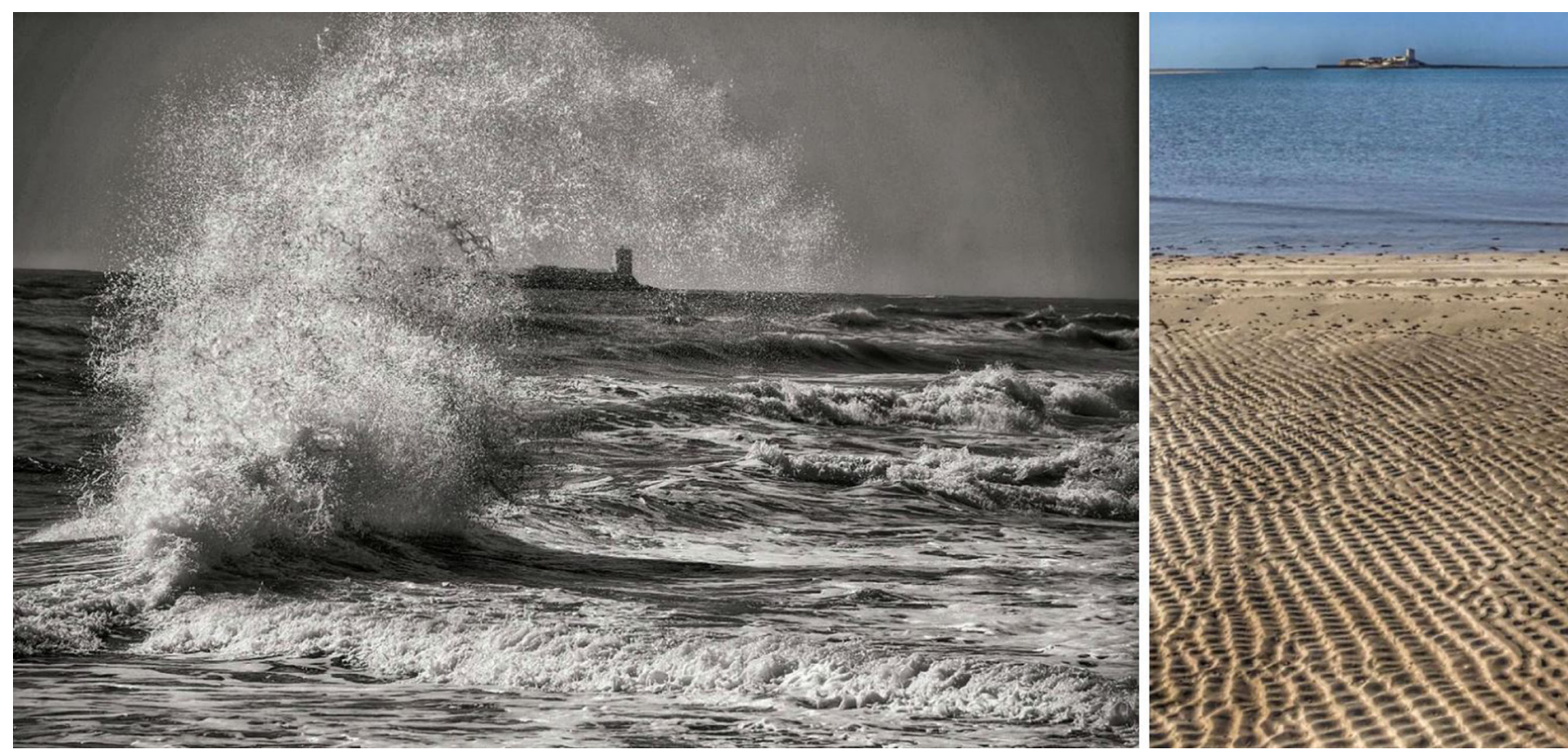

Figura 1. Erosión y sedimentación han modelado la costa actual, proceso activo alterado por la acción antrópica que produce cambios en la dinámica. (Fuente: J.M. Higueras y J. Llerena).

Revista Atlántica-Mediterránea de Prehistoria y Arqueología Social 22, pp. 309-335

Universidad de Cádiz 
la influencia que sobre la misma tuvieron los procesos naturales y antrópicos, o los elementos construidos a lo largo de los siglos en el litoral con fines de obtención de recursos, transporte y defensa, muchos de los cuales se han preservado, conformando un rico patrimonio cultural marítimo, en gran parte olvidado. (Márquez, 2016: 32).

Describimos brevemente los elementos patrimoniales documentados en el término, agrupándolos según el territorio en el que se sitúan, acotándolos en un triángulo formado por los tres frentes principales que rodean la isla (océano, caño y bahía interior) y un cuarto frente más difícil de delimitar, los terrenos inundables (Figura 2).

\subsection{El Caño de Sancti Petri y su desembocadura}

La red de caños de agua marina que discurren por las marismas, han constituido vías de navegación interna, así como salida hacia el Océano, con indicios desde la Prehistoria. El principal, el caño de Sancti Petri, que separa la isla del Continente, entrando entre la Punta del Boquerón a babor y Punta de las Piedras Bermejas a estribor, si venimos navegando. Recorre unas 11 millas de forma sinuosa hasta el interior de la bahía, en La Carraca, estando fuertemente condicionado por las mareas, cambiando drásticamente su apariencia, variando su cauce de $250 \mathrm{~m}$ en bajamar a 500 metros en pleamar. Actualmente es navegable en toda su longitud para embarcaciones de poco calado.

El patrimonio arqueológico subacuático guardaría relación con esta actividad fluvial, de comunicación y explotación de los recursos a lo largo de los siglos: fondeaderos, embarcaderos y puentes (desde los pasos de barca hasta el puente Suazo), pero también con la defensa del territorio, protegiendo la puerta trasera de la bahía, baterías y fortines, e infraestructuras portuarias, como el carenero para buques de la Armada Real (TM Puerto Real), y debido a todo este tránsito y a los escollos que presenta, es también zona de numerosos naufragios y siniestros.

Una cadena de bajos rodea el islote (Figura 3) en todas direcciones, accidentes que están recogidos en las cartas y descripciones náuticas de esta zona peligrosa para la navegación:

- Hacia el norte se extiende El Arrecife, escollera natural o plataforma de abrasión, que emerge $1700 \mathrm{~m}$ y enmarca una canal de muy poca profundidad, llamada del Boquerón, que es utilizada como refugio con fuerte viento de levante por el peligro que supone
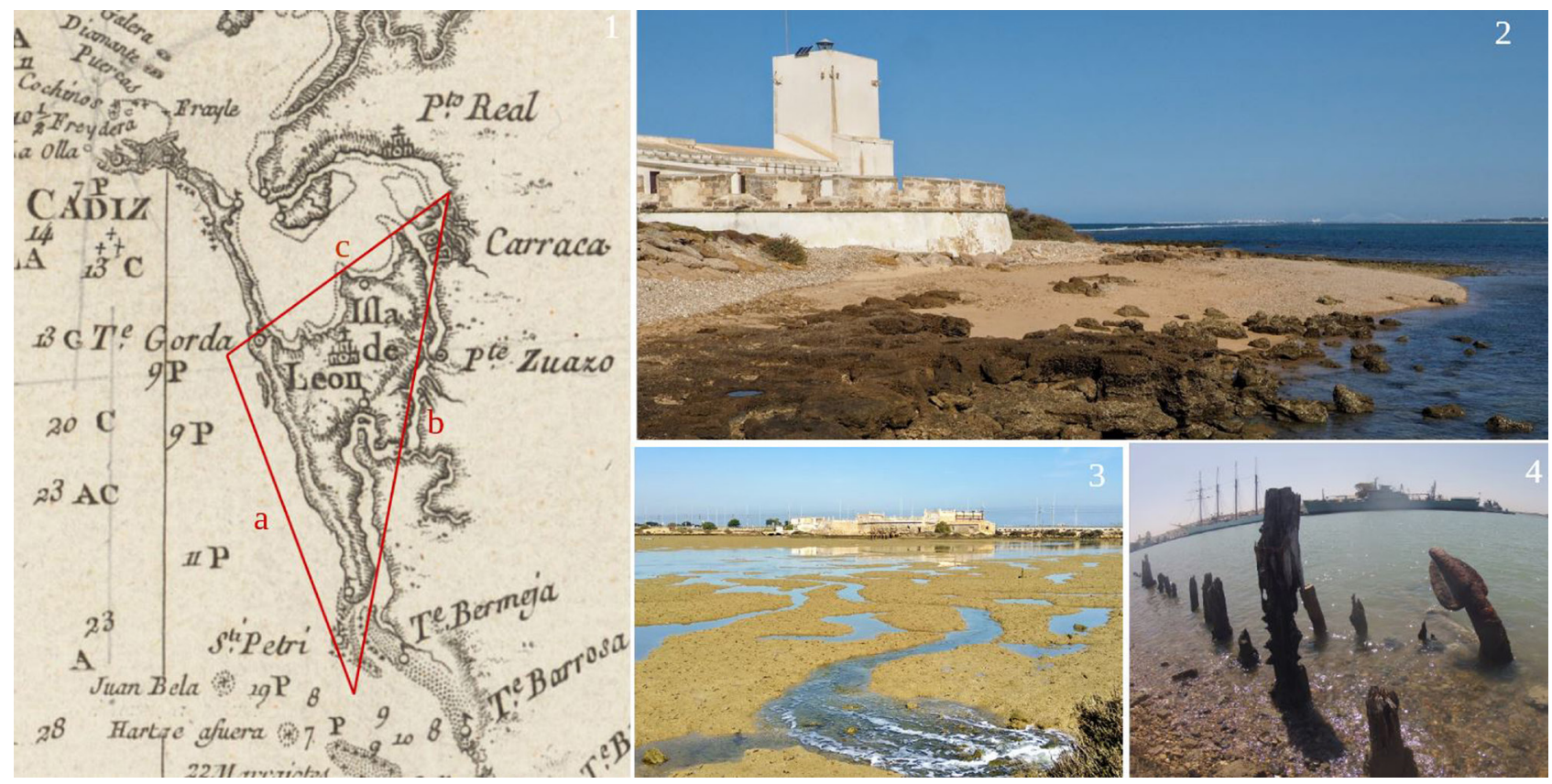

Figura 2. 1. Detalle de los tres frentes (Oceano-a, Caño-b y Bahia interior-c) en la Carta esférica de la costa de España desde cabo de San Vicente hasta punta de Europa 1786 de Vicente Tofiño; 2. Castillo de Sancti Petri y frente atlántico; 3. Rio Arillo; 4. Interior de la Bahía-La Carraca.

(Fuente: Archivo gráfico IAPH - CAS). 
la barra de Sancti-Petri, con los escollos La Redonda y Moguerano que descubren en bajamar y en la boca sur del mismo, la piedra Trabuco.

- Al Sur se encuentran Los Farallones, Grande y Chico.

- Al Oeste, La Piedra o Bajo de La Arihuela.

- Al Este, La Punta de las Piedras , la zona más peligrosa por los obstáculos que suponía al intentar entrar en el Caño, debido principalmente al Bajo de Rompetimones, otros obstáculos de menor entidad, La Pulpera, Los Morenatos, agravado todo ello por la dificultad añadida de las corrientes en esta zona, que pueden llegar a alcanzar intensidades de 4 a 5 nudos.

¿Pero cómo sería este paisaje en la antigüedad? Hasta ahora se han planteado diversas propuestas de reconstrucción paleotopográficas del islote. Una de ellas señala la unión del islote con la tierra firme de la zona de Torre Bermeja (Chiclana), hasta el 100 a.C. a través de una amplia plataforma rocosa de la que quedarían restos en los bajos rocosos (Moguerano, la Pulpera y Rompetimones), y que se encontraría separado de tierra firme en el 300 d.C., sugiriendo asimismo, que el caño desembocaría en un punto más al norte del islote (en
Alonso, 2009: 18; Gracia et al., 2017: 53, fig 5); y otra teoría, que defiende que este carácter insular lo tendría desde época antigua y que debe tenerse en cuenta a la hora de analizar las ocupaciones antiguas, todo el terreno perdido por la erosión durante miles de años (Arteaga, 2008: 43 y 74; Gómez, 2019: 264; Sáez, 2012: 26-29).

Se trata de un paisaje muy cambiante, como hemos dicho anteriormente, no solo por los elementos moldeadores del paisaje. El efecto antrópico ha modificado su curso a lo largo de los siglos, pero fue la construcción del puente de piedra Suazo, actuando como barrera o compuerta, el que más contribuyó a su aterramiento. Incluso fue directamente culpado ya desde el siglo XIX, ya que en el debate en el Congreso sobre los presupuestos se trataba el "aterramiento que sufren los caños de la Carraca, producidos por los arrastres del Guadalete, por haberse cegado obedeciendo a exigencias estratégicas, la boca de Sancti Petri,...", proyectando entonces la limpieza de la barra, la apertura del caño del Carrascón y la construcción de un puente de hierro, en sustitución del anterior de piedra (El Imparcial, 26 de Mayo de 1892; El Siglo Futuro, 27 de mayo de 1892).

La barra de Sancti Petri ha supuesto durante siglos un claro peligro rodeada de todos estos escollos y los aterramientos cambiantes. El bali-
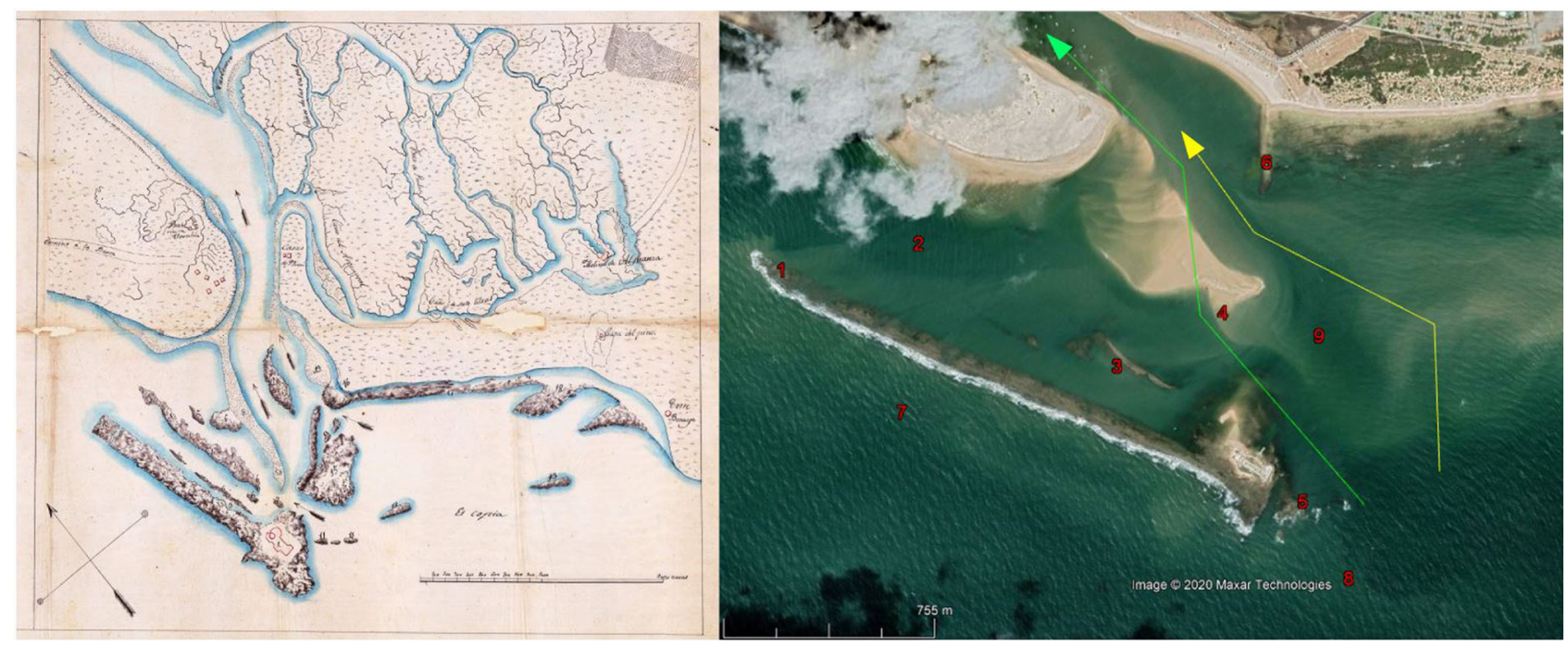

Figura 3. Plano de posición del Castillo de Sancti Petri y desembocadura del canal del mismo nombre, Cádiz, Comandancia de ingenieros, signatura E-2-10-1. (Fuente: Colección Pettengui, Archivo Histórico Provincial). La ortofoto muestra la situación de los bajos citados en el texto: 1. Punta del Arrecife; 2. Canal del Boquerón; 3. Moguerano y La Redonda; 4. El Trabuco, 5. Los Faralllones; 6. Punta de las Piedras; 7. La Arihuela; 8. Bajo de Fuera; 9. Rompetimones. (Fuente: Imagen Google fecha imagen 6/8/2020). 
zamiento de unos bajos, la voladura de otros, y el dragado de los puntos conflictivos, fue un proyecto que se fue gestionando lentamente, durante más de 25 años, demandándose en continuadas ocasiones, "ya que no pasan años ni épocas, sin que se registren grandes siniestros, produciendo victimas de la humilde clase de pescadores", en carta del Alcalde al Ministro de Fomento, recogida en prensa de la época (La Dinastía, Cádiz, 22 de diciembre de 1915, año 2, no 64 ).

\subsection{La recta playa al frente del océano}

El sustrato rocoso del pleistoceno, fracturado y elevado por los movimientos tectónicos, emerge en algunos puntos como plataforma de abrasión. Presenta una barrera frente al mar que protege la barra arenosa, anteriormente más ancha y elevada, detectándose en investigaciones recientes un retroceso que tal vez pueda superar los $250 \mathrm{~m}$ en algunos tramos (Arteaga et al., 2008; Bethencourt et al., 2011: 49; Gracia et al., 1999, 2000). En paralelo, a unos 3-4 km de la costa, se localiza el bajo rocoso El Placer de los Mártires, separado de la línea de costa por una depresión (Gracia et al., 1999: 70).

El efecto erosivo de un tsunami en esta costa, podría ser devastador y no habría barrera que la protegiera, aunque el daño causado por los temporales en invierno, por ser continuos y a lo largo de los siglos, es el principal responsable de los daños en el perfil de esta playa.

\section{Una ligera subida del nivel del mar unida a una mayor energía por parte del olea- je favorecen la erosión de la parte más alta de la playa de forma que esos sedi- mentos pasan a una zona sublitoral más profunda y luego sirven de alimentación a la propia playa durante épocas de buen tiempo. (Badají, 2009: 143).}

Esta costa ha sido escenario de desastres navales de gran transcendencia histórica (Alonso y Márquez, 2013). Entre estos destaca el pecio de Camposoto, (Figura 4) identificado por el Centro de Arqueología Subacuática del Instituto Andaluz de Patrimonio Histórico (CAS-IAPH) como los restos del navío francés Fougueux, participante en Trafalgar, que "desarbolado, sin gobierno y a remolque como presa de un navío inglés, se enfrentará a su última contienda contra los embates de un fuerte temporal que lo arrastró contra los bajos rocosos de Sancti-Petri" (Rodríguez et al., 2013, 2016).

También incluimos en este frente el denominado Pecio del Cobre, que contará con un artículo por parte de su descubridora en esta misma publicación de la revista RAMPAS, y el Sverige, al que un temporal sorprendió cerca de Cádiz. La combinación de los fuertes vientos con averías y bajos rocosos fue fulminante y naufragó en 1738: "poco más de un kilómetro del castillo, sobre el arrecife que se prolonga hacia el norte aproximadamente una milla, yacía encallado y desarbolado un enorme navío de guerra" (Gandul, 2006: 432-433, 2018) que contó con actuaciones de rescate muy documentadas, recogidas en una breve reseña sobre la historia y el entorno político por Sáez Espligares (2002).

En paralelo al Proyecto realizado desde el Centro de Ensayos de Torregorda para la recuperación del tramo costero de Camposoto a Torregorda, y en colaboración con la Unidad de Buceo Científica y Tecnológica de la Universidad de Cádiz, se llevó a cabo una actividad arqueológica preventiva (González, 2009) que localizó diversas agrupaciones de cañones. La cercanía del pecio del Fougueux, planteó la posibilidad de responder a preguntas sobre el paradero de gran parte del barco, por lo que desde el CAS se realizó una nueva intervención de prospección en la zona (Rodríguez y Martí, 2010). A raíz de estos trabajos, se ha concluido que cuatro de las agrupaciones de artillería (grupo III con 18 cañones, grupo IV con 23, grupo V con 3 y grupo II con 1 cañón) (Figura 5) podrían pertenecer a parte del naufragio, y que los restos fragmentados hubiesen ido a la deriva empujados por la fuerza del viento de SO en dirección NNE-SSE. Su localización actual a unos $400 \mathrm{~m}$ de la playa, marcaría la antigua línea de costa visible en la cartografía histórica de 1787 (Bethencourt et al., 2011: 48).

Tal como señalamos anteriormente, el patrimonio subacuático no solo se localiza bajo el agua, sino también en la rompiente, playa y zona de dunas. Como ejemplo de esto último podemos citar los restos en Camposoto que podrían proceder de una factoría de salazones y alfares en la zona, que se cubren y descubren en esta playa, -material constructivo (sillería, mampuestos, ladrillos, tégulas), ánforas e incluso un desecho de cocción que sugiere la presencia de alfares (Sáez y Sáez, 2011: 26-29). También se conservan en la zona restos del Camino del Arrecife "como mudos testigos del férreo dominio de la naturaleza sobre los productos antrópicos" (Bruquetas, 2017: 53). 


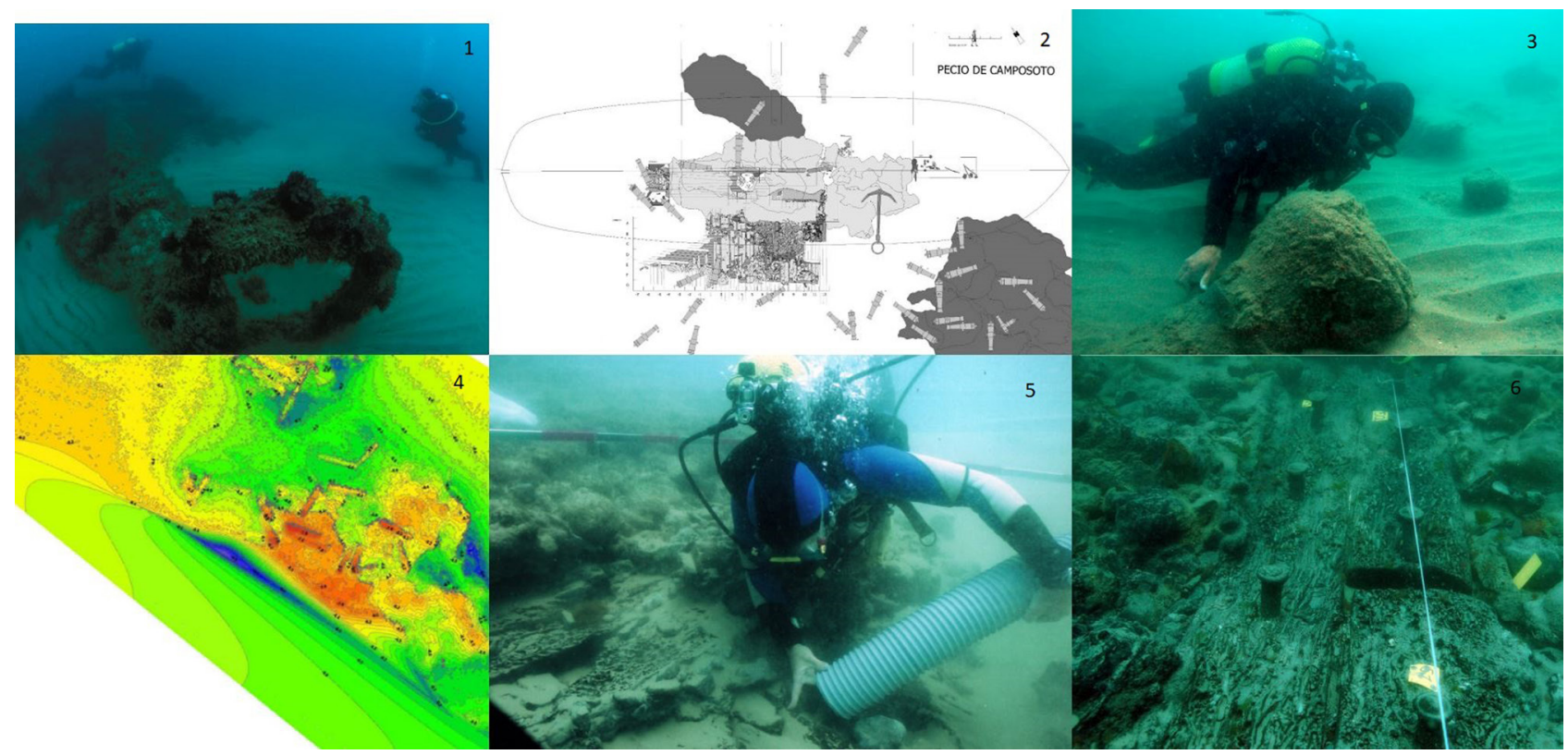

Figura 4. Campañas de Actuación Arqueológica Puntual Camposoto: 1. Ancla del Fougueux; 2. Planimetría del pecio; 3. Detalle de uno de los 31 cañones localizados; 4. Imagen multihaz del pecio; 5. Realización de sondeo; 6. Detalle de la estructura naval conservada (Fuente: Rodríguez, 2013, 2016; Archivo gráfico IAPH-CAS).

\subsection{Bahía interna}

Se encuentra abrigada de la acción directa del oleaje y su morfología ha condicionado la navegación por este sector: un canal natural que conduce al caño de Sancti Petri, junto al Arsenal de la Carraca, una zona de poca profundidad, pero que tuvo mayor calado en época moderna, con un dique en la zona de Santibáñez (Márquez et al., 2016: 40).

Los elementos patrimoniales más significativos de este ámbito son: zonas de fondeo, estructuras portuarias y embarcaderos, elementos de señalización marítima (faros y balizas), infraestructuras portuarias, instalaciones para la construcción naval (astilleros, diques de carenas), puntos de abastecimiento y aguadas, caseríos y fábricas, polvorines cantera y muelles, lazareto, fondeo de invierno, molinos de marea de Caño Herrera y de San José, además del Arsenal de la Carraca, a la entrada del Caño de Sancti Petri (ver Chías y Abad 2011; Márquez, 2016, para mayor información).

La zona interna y en concreto el entorno de La Carraca, es un paisaje muy antropizado con terrenos ganados al mar, un islote originado por la acumulación de fangos, como se ha sugerido, en torno a una embarcación del mismo nombre allí abandonada (Quintero, 2000: 26). Se han extraído restos de cascos de barcos de esta zona, que se interpreta como un cementerio de barcos, algunos hundidos de forma intencionada para obstaculizar la nave- gación. Sabemos que entre 1587 y 1596 se hundieron cinco en la entrada de La Carraca, cuatro en el interior y tres fragatas en el caño de Sancti Petri (Quintero, 2000: 37-40) acciones qu contribuyeron al aterramiento de esta zona, que había contado con hondura y disposición, agravado por la cantidad de maderas, lastre de barcos y basura que se había venido vertiendo. En el XIX navío Miño y la urca Librada fueron hundidos en las proximidades de la Punta de la Clica (Márquez, 2008: 40), aunque empezaron a tomarse medidas encaminadas a la limpia de fondos, principalmente dragados pero también prohibiciones (Quintero, 2000: 38-42).

Este frente fue escenario de combates, como el de la Poza de Santa Isabel, que se desarrolló el 14 de junio de 1808 frente al Arsenal de La Carraca y rindió a las fuerzas militares napoleónicas sin hundir ningún barco, aunque sí quedarían bajo el agua restos de la artillería. Las cárceles flotantes, los llamados pontones, fueron fondeados en el saco interno de la Bahía de Cádiz, frente a Caño Herrera, Punta de la Clica y Casería de Ossio (Márquez, 2008, 2020: 40).

Pendiente de valorar, pero ya protegido por la figura de Zona Arqueológica (ZA) de La Carraca, se encuentra la Isla de San Agustín frente a la Carraca, zona "que la alta mar cubre" como se recoge en la cartografía de la época, donde se ha observado una gran concentración de material cerámico, anclas y cadenas de hierro (localizado por Sáez en 

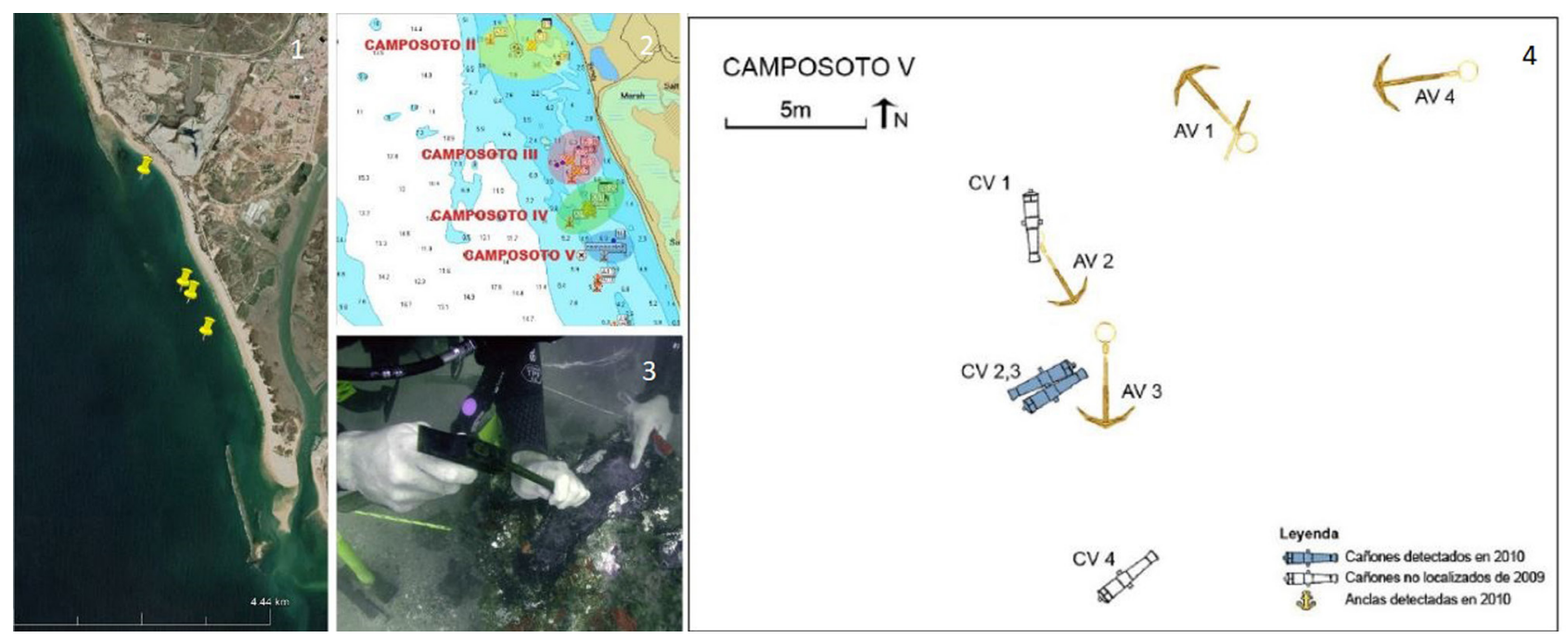

Figura 5. 1. Localización proyecto; 2. Mapa distribución de elementos arqueológicos; 3. Proceso de desconcreción de la faja alta de culata de una pieza de artillería; 4. Planimetría preliminar del Grupo V. (Fuente: Fondo Gráfico IAPH-CAS, Rodríguez y Martí, 2010; Archivo gráfico IAPH-CAS).

2017). Esta evidencia podría corresponder con un proyecto del siglo XVIII destinado a depósito de anclas y lastres de navíos (Quintero, 2000: 125).

\subsection{Terrenos inundables}

Hemos acotado los tres vértices acuáticos de la Isla, pero faltaría describir los espacios inundables, que rellenan el citado espacio. Estos han sido muy modificados debido a la intervención humana, que ha desecado marismas, cegado caños, construido salinas, embarcaderos, caminos, puentes, etc., intensamente desde época medieval, para ganar espacios, por lo que el entramado natural ha sido sustituido por una red de canales con el ciclo natural alterado y el paisaje modificado.

El lecho de arcilla y barro, robado al mar, es un terreno difícil para la construcción, por la movilidad que dificulta la cimentación (Bourgoing, 1789, en Chias y Abad, 2011: 83). Sin embargo, desde antiguo, se han encontrado estrategias para adaptarse al medio, como el empleo de postes de madera clavados en el fango como soporte para el acueducto romano, que indica que todo ese sector estaba ocupado por una amplia marisma emergida (Fernández, 2008: 202-206).

Clima, medio ambiente y recursos se unen para dotar a esta zona de un patrimonio natural excepcional: esteros y salinas, caños que comunican y aguas que mueven molinos (Rio Arillo, San José y Arrierillo), siendo frecuente el hallazgo de restos arqueológicos, ya sean aislados o formando parte de estructuras como acueductos, pecios, muros de salinas, restos de la calzada romana o embarcaderos (Bernal, 2005: 213).

Estos terrenos inundados por las mareas y atravesados por una maraña de caños constituyeron linea defensiva en el asedio francés, convertidos en escenario de batallas donde se rechazaron ataques desde las líneas de artillería apostadas (Chías y Abad, 2011: 133).

\section{De las primeras exploraciones a las actua- ciones arqueológicas regladas}

Las exploraciones arqueológicas que en
breve plazo convendría realizar hacia
este paraje, no podrán menos de llegar á
un resultado vivamente apetecido por la
ciencia contemporánea. (Vera y Chilier,
1888).

Todo el entorno de la Isla ha sido muy fructífero en hallazgos arqueológicos, encontrando huellas de la presencia humana a lo largo de diferentes épocas en todo el litoral, marcando claramente zonas de alta intensidad como la desembocadura del Caño de Sancti Petri donde ya, desde mediados del XVIII, se planteaba la necesidad de emprender campañas de prospección. Por ello nos centraremos en esta zona emblemática, y remitimos a la abundante bibliografía (Álvarez et al., 1981, 1994a, 1994b; Blanco, 1985; Blázquez, 1954, 2001; Corzo, 1991, 1992, 2005; Gar- 
cía y Bellido, 1963, 1987; Jiménez, 1971; Marín, 2001, 2011; Pemán, 1941; Perdigones, 1991; Quintero, 1906; Romero, 1934; Sáez, 2009; Sáez y Sáez, 2011; Sáez et al., 2005; Sáez Espligares, 2017; Schulten, 1925, entre otros) que recoge las citas de fuentes clásicas - Estrabón; Pomponio Mela; Fabius Maximus, Polibio, Artemidoros, Poseidonio, Apollonio de Tyana, entre otros - sobre las fuentes medievales (Abellán, 1996) y las modernas (Ceán-Bermúdez, 1832; Flórez, 1753; Horozco, 1598; Ponz, 1794, entre otros). Todas ellas relatan la fama y antigüedad del templo, El Herakleión Gaditano, historias de restos arrasados por el mar, la escasez de fuentes arqueológicas disponibles, su importancia religiosa y político-administrativa, su decadencia, incluso su posible estructura arquitectónica y su funcionamiento, ingresos y saqueos. Aunque hay que señalar, que al igual que pasa con la ciudad de Cádiz y su origen fenicio, se ha mantenido la imagen idealizada basada en las fuentes clásicas sin someterlas a una lectura crítica, interpretada en ocasiones según los intereses (Niveau, 2019: 7).

Nuevas técnicas interdisciplinares de investigación deben ir aportando posibles respuestas no solo a la evolución geomorfológica, también al desarrollo de los acontecimientos, incluso en algunos casos, dando protagonismo a los desastres naturales como causa traumática que rompe el normal desarrollo de asentamientos costeros, como el ocurrido entre el 218- 209 a.C., que cuenta con un claro registro en la Bahía de Cádiz (Luque et al., 2002, en Gómez et al., 2015: 58). Este evento ha sido relacionado con el relato de Silio Itálico (III, 46-48) sobre Anibal en Santuario de Melqart, quien presenció como el mar subió e invadió la tierra y las orillas cercanas, dejando al retirarse las aguas los navíos abandonados (García y Bellido, 1963, en Gómez , 2015: 69).

Pero no solo el mar ha jugado su papel en desgranar los restos del pasado:

Se tiene por cierto que el Océano ha desmoronado buen parte del Promontorio Herculeo, y también se sabe que con aquella peña se hizo parte del puente de Zuazo. El templo, o sus ruinas no tiene duda que se las sorbió el mar, como no la hay en que se ha extendido algunas leguas desde Cádiz hasta aquí sobre la tierra. (Horozco 1929: 208; Ponz, 1792-1794: 47).
La piedra del Islote se utilizó para el arreglo de la Muralla de Vendaval en 1697, y según la documentación de la época, después de 2500 barcazas la piedra llegó a agotarse (Lantery, 1673-1700 en Ruiz y Jiménez, 2016: 141).

\subsection{Hallazgos fortuitos tras la bajamar. Noti- cias del siglo XVIII}

Se suelen citar a Ambrosio de Morales (1575: 223) como una primera alusión a la existencia de restos bajo el mar en esta zona de Sancti-Petri (García y Bellido, 196: 73; Gallardo, 1992: 79), pero diríamos que se refieren al litoral de la actual ciudad de Cádiz, ya que dice "aquella isla" donde "cuando la mar está muy clara y sosegada, se parecen en lo hondo edificios antiguos, y creen ser de la ciudad que como Estrabón refiere, hubo en aquella isleta allí vecina".

Si son numerosas las noticias que en el siglo XVIII recogen hallazgos fortuitos, ya que, como García y Bellido señaló, la "pesca de antigüedades" era un hecho frecuente en la zona (Sánchez-Cantón, 1943: 220), además de auténticas descripciones de yacimientos, que se visualizan después de alguna retirada anormal de las aguas (García y Bellido, 1964; Gallardo et al., 1992; Sáez 2012; Sáez Espligares, 2017), encontrando entre los relatos de los eruditos locales y foráneos, conexiones, así algunas contradicciones en fechas.

Se recuperaron objetos y se vieron columnas según recogen las Actas del Cabildo de 1704 y en la década de los treinta a bajada del mar se habla de ruinas sumergidas, cimientos y paredones, pero con escasos restos materiales que lo demuestren. Sí conservamos la imagen de dos estatuillas recuperadas gracias a que el Marqués de la Cañada, Guillermo Tirry, las incorporó a su museo y las mandó dibujar al conde Caylus (Gutiérrez, 1771, en Salas, 2003: 493). Conservado en la Biblioteca Capitular-Colombina de la S.I. Catedral de Sevilla, el texto "Descripción de las Antigüedades del Gabinete del Marqués de la Cañada, hechas por él mismo; habiéndolas mandado dibujar en 13 láminas, para remitir a Francia, a el Conde Kailus, por Abril of 1764". Anne-Claude-Philippe de Tubières, conde de Caylus, en su obra Recuil d'antiquités egyptiennes, etrusques, grecques, romaines et gauloises, (1767), describe las dos estatuillas procedentes de Sancti Petri, que incorporó en la Lámina XCVII (Rodríguez, 1990: 95) por cortesía hacia el Marqués, aunque señala 
que las proporciones no eran correctas. Contiene un error en la fecha, ya que las sitúa cronológicamente en 1631 (http://caylus-recueil.tge-adonis. fr/) (Figura 6).

En una carta de Gutiérrez de los Ríos, Real Academia de la Historia, dirigida a Villacevallos y Vera, anticuario y coleccionista de antigüedades, detalla hechos de los que fue coetáneo relacionado con uno de estos eventos, el 4 de febrero de 1731: "Con la violencia del desenfrenado golpe del mar se descubrió en Santi Petri, a tres leguas de esta ciudad, una estatua de bronce de medio cuerpo de bajo, y un brazo de otra estatua, y una peana de lo mismo, y otras diferentes piezas, como manos de león, y cenefas las cuales parecían haber servido en algún trono o altar", describiendo el resto de las piezas con mucho detalle (puertas, cornisas, figuras , monedas, mesas de piedras de colores, etc..)". Interesa resaltar que se nombraron inspectores para el reconocimiento de la zona, acudiendo con buzos que hicieron excavaciones pero que no recuperaron más allá de algunas monedas, señalándose entonces al capitán y soldados del castillo como responsables de ocultar los materiales (Biblioteca Capitular y Colombina de Sevilla, 59-344: fols. 25 y 25v, en Salas, 2003: 68). El Cabildo sufragó los gastos ocasionados, con la intención de recuperar restos (Cabildo ordinario del 7 de marzo de 1731, fol 128, en García y Bellido, 1964 ; Bruquetas, 2013, 2 ; Acta del 28 de abril, fol 206

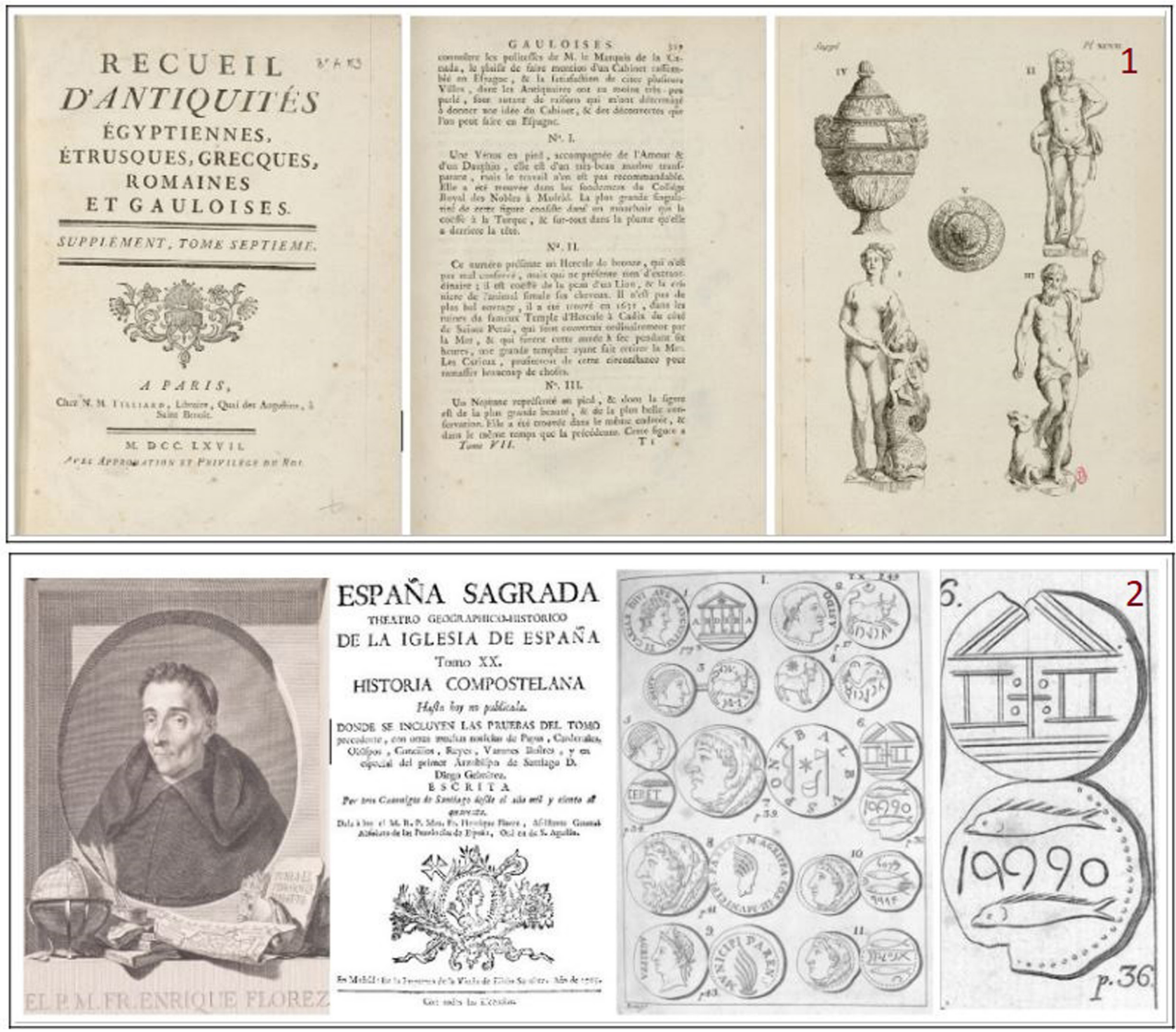

Figura 6. 1. Estatuillas de bronce del museo del Marqués de la Cañada, en las láminas del conde Caylus (1767); 2. Medalla con dos Atunes y templo de cuatro columnas en estampa 1 no 6. (Fuente: Flórez, España Sagrada, 1753). 
y ss). Algunos lo han considerado la primera excavación arqueológica subacuática de la que se tiene conocimiento en España (Pérez, 2017; Salas, 2003: 68) pero se trataría en todo caso, de una inspección destinada al rescate de objetos antiguos y valiosos.

Se sucedieron otros hallazgos: en 1735 se recuperó al levantar un ancla en las inmediaciones del Castillo, una estatua de mujer recostada sobre un lado y un animal parecido a un zorro junto a ella (Crouley 1795; García y Bellido, 1946: 74), además de avistar ruinas y antiguallas, noticias que recogen autores posteriores (Ceán, 1832: 227-228; Gallardo, 1992: 81).

Uno de los eventos de alta energía que afectó a este litoral, muy bien documentado, fue el gran tsunami asociado al terremoto de Lisboa del 1 de noviembre 1755 , que causó multitud de estragos. Impresionan cada uno de los adjetivos de un relato de lo que aconteció -día sin el menor soplo de viento, caliginoso sol, espantoso ruido, rugidos del mar sobrenatural y precipitado-:

Se descubrió venía caminando por frente de la torre del castillo de Sancti Petri, una ola de agua o (según la vulgaridad de los naúticos) cáncamo de mar en forma de muro, de elevación otro tanto más de altura que la del citado Castillo,.. llegaron a la barra, chocando impetuosamente con las rocas de ella, y disponiéndose el agua se introdujo, ocupando toda la parte de tierra, y hueco del río de Sancti Petri, ... sumergió y ahogó a cuantos cogió, sus bagajes y carruajes, haciendo por tres veces el mar impetuosas y dilatadas retiradas y salidas de sus límites... (Martínez, 2001, pág. 275, documento 281, Alonso Valdés y G. Excelentísimo Señor Don Antonio de Azlor [= Gobernador de Cádiz, quien lo remitió el 25-XI-1755).

En los relatos anteriormente citados se entremezclan noticias, creando una cierta confusión en cuanto a los hallazgos, fechas y lugares de procedencia: Antonio Ponz, en su "Viage de España, hace referencia del hallazgo de algunas estatuillas antiguas, de bronce, citando en concreto un Hercules y un Neptuno, ect. encontradas en la playa de Sancti Petri, en la resaca que el mar hizo el 1 de Noviembre de 1755 con motivo del terremoto y que pasaron a la colección del Marques de la Cañada a la de D. Sebastián Martínez de Cádiz, en (García y Bellido, 1964: 75), incluso cita un "borroncillo" (¿borrador?) de una estatua que interesaría localizar (Ponz, 1792-1794: 48). Pero las estatuillas de bronce citadas podría corresponderse a las de la resacas de los años 30 que hemos nombrado anteriormente, mas que relacionarlas con las estatuillas orientalizantes, como algún investigador se planteaba (Blanco, 1985: 208).

Ese mismo año del terremoto se produjo una fuerte bajamar, en la que los soldados, localizaron dentro de un edificio una gran estatua de bronce que trasportaron hasta el Castillo para trocearla y venderla como chatarra, recuperando D. Guillermo Tirry un pie con parte del tobillo que guardó en su colección. (Gallardo, 1991: 81; Salas, 2003: 314; Solé, 1965: 146), observándose de nuevo columnas medio soterradas en la arena (García y Bellido, 1964: 75; y en Diario de Madrid de 7- 8 de abril de 1808).

\subsection{Hallazgos del siglo XIX. Paraje en el punto de mira}

En el siglo XIX tan solo conocemos la referencia a una moneda fenicia recuperada en la desembocadura del Caño de Sancti Petri, una sola moneda que sin embargo, llevó a que un académico expresara el deseo de explorar en el fondo del río de Sancti Petri (Cuaderno V. Mayo, 1888 Noticias, en Boletín de la Real Academia de la Historia, http://www.cervantesvirtual.com/nd/ark:/59851/bmc1g195).

La zona estaba en el punto de mira de varios eruditos, que consideraban que las exploraciones arqueológicas en este paraje (isla Heraclea, ó de Sancti Petri, y su famoso templo de Hércules), mostrarían un resultado "vivamente apetecido por la ciencia contemporánea" (Cuaderno V. Mayo, 1888 Noticias Boletín de la Real Academia de la Historia). El intercambio de correspondencia de algunas de las principales figuras de la época lo demuestra, como por ejemplo la carta que Francisco de Asís Vera y Chilier conservador-director del Museo Arqueológico de Cádiz, envía al fraile jesuita Fidel Fita, epigrafista y miembro de la Real Academia de la Historia, pidiéndole que realice una visita y que señale, a partir de la observación del lugar y los planos, el sitio donde buscar el templo de Hércules. En su respuesta indirecta, Fita señala su creencia que el templo debía estar sumergido bajo las olas del Océano (Abascal, 1949: 74). 


\subsection{Hallazgos $\mathrm{y}$ actuaciones del siglo $\mathrm{XX}$ hasta los 70. El ocaso de los emperadores}

Según narran las fuentes clásicas, el templo recibió la visita de personajes ilustres, como Aníbal en el año 219 a.C. (Liv. 21. 21) para realizar votos, Fabio Máximo en 145 a.C (App. Ib. 65) y por César en el 68 a.C. (Suet. Caes. 7) muestra de su fama entre fenicios y romanos (Blázquez, 2001: 300).

Nos adentramos en el siglo XX para conocer los detalles del hallazgo de la escultura de mármol de un emperador divinizado, que reproduce fielmente el modelo iconográfico del emperador Trajano (98-117) divinizado, hallada en Itálica (CERES), aunque podría representar también a Adriano (117-138), y que fue localizada en el bajo de Moguerano, en 1905 (Figura 7).

Romero de Torres en su Catálogo recogía con detalle la noticia, observando que era un hecho frecuente que aparecieran restos en las redes:

En 8 de agosto de 1905, hallándose trabajando a 35 pies de profundidad el buzo Sr. Escacena, en la especie de rotonda que forman las piedras, entre el bajo llamado Munerano y el castillo, en dirección de los restos de la calzada, según la relación de dicho buzo, en tal lugar, creyó ver graderías y escalones en perfecto estado de conservación; y como a unos 20 metros reparó en un bulto que al pronto le pareció el cuerpo de un ahogado sujeto por las piedras; pero al aproximarse, pudo apreciar que era una estatua de mármol, la cual, con ayuda de otros compañeros, fue amarrada y sacada con cuidado, trasladándola a la Capitanía del Puerto de Cádiz. Mide ésta 1,90 m. de altura, y carece de cabeza y brazos; está desnuda, y sobre el hombro izquierdo tiene pegada la clámide en actitud reposada, y junto a su pierna derecha hay el tronco de un árbol. (Romero de Torres, 1908-1909: 99).

En la antigua ficha del Inventario General del Museo de Cádiz no 4583, en procedencia citaba: "Hallado el 8 de Agosto de 1905 por los tripulantes del vapor de pesca "San José y El Niño" en el sitio llamado Arrecife del Castillo de Sancti Petri a unos tres cables del castillo y a tres brazas de profundidad, Donación del Márquez de Comillas (se conserva el acta) Fecha de ingreso 1913 (1908)". Sin embargo, este barco esta relacionado con otro hallazgo posterior, un attis hilaris del tipo danzante, una escultura de bronce.

En la documentación de la época, y en la posterior se entremezclan diferentes fechas de los hallazgos -17 de junio de 1905 (Diario de Cádiz), 8 de agosto de 1905 (Romero de Torres)-, lugares concretos de procedencia- Moguerano o Numerano (Quintero y ABC), Rompetimones o zona poniente del arrecife, o cerca de la calzada que unía el santuario de Hércules Gaditano a la ciudad de Gades (Expediente 1905/62 CERES) el mismo sitio que la estatua thoracata (Rodríguez, 1990: 94-95); sus halladores y las circunstancias -los faluchos de pesca San José y Niño, o encontrada de forma casual por D. José Alvera en agosto de 1905 (CERES).

La prensa recogió el entusiasmo de los pescadores al localizar la estatua de bronce del Atiis entre las redes del:

Falucho de gallineras, patroneado por el Sr Torrejón (...) al levantar para recoger la pesca, notaron los pescadores gran resistencia, teniendo necesidad de hacer superiores esfuerzos a los de ordinario para meterla a bordo. Conseguido esto, un objeto voluminoso que atestaba forma humana y de dimensiones aproximadas a las de un niño de pocos meses fue recogido del arte. Limpio y desprovisto de todas las adherencias y mariscos de todo genero, se vio era una pequeña estatua de bronce de unos cuarenta o cincuenta centímetros de alto, ya carcomida por la acción del tiempo y las aguas (...) El sitio en que fue levantada de las profundidades del mar, hallase en la parte de poniente del arrecife o antiguo camino romano de Sancti-Petri a Cádiz y en las inmediaciones del castillo de aquel nombre (...) Cuando la estatua fue traída a tierra hubo entre las gentes del populoso barrio de las Callejuelas gran revuelo y contento creyendo pudiera ser del codiciado metal oro. No había tal, es como dijimos de bronce y pesa 11 kilos. Además de la cabeza le faltan los pies, si bien conservaba uno de ellos que se separó al despojarles las adherencias y mariscos. Calza algo así como un zapato de forma antigua. (Diario de Cádiz, 17 de junio de 1905). 


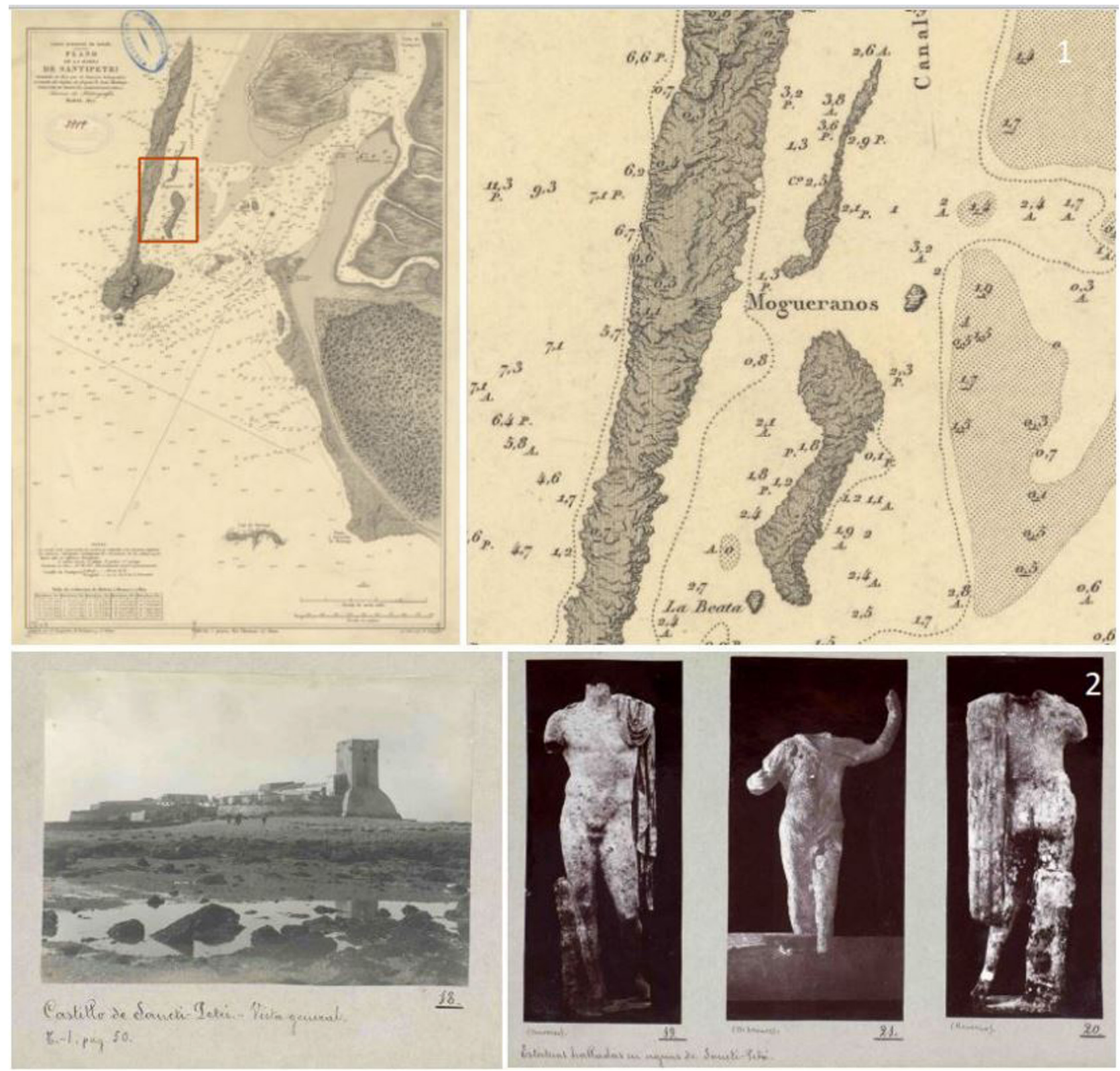

Figura 7. 1. Plano de la Barra de Sancti-Petri (Montojo, 1872) se recogen enfilaciones de entrada, cotas batimétricas, tipos de fondo (Arenas, Fango, Piedra y Cascajo). Detalle de uno de los "peligros que se cubren y descubren” bajo de Mogueranos; 2. Castillo y esculturas de 1905 antes de su restauración.

(Fuente: Romero de Torres, 1908-1909).

Se conservan cartas de la Real Academia de la Historia a la Comisión de Monumentos Históricos y Artísticos de Cádiz, en 1907 pidiendo remisión de fotografías de las referidas estatuas y que se procure averiguar el paradero de las desaparecidas (14 de Mayo de 1907, http://www.cervantesvirtual.com/nd/ark:/59851/bmc1z5p6).

Las dos estatuas habían sido depositadas, a ruego de la Comisión de Monumentos de Cádiz, en la Comandancia de Marina, donde se anunció el hallazgo convocándose a las personas que se consideran con derecho de posesión, siendo posteriormente entregadas sus halladores, quienes las vendieron, primero la de bronce, que se encuentra desde entonces en el Museo Arqueológico Nacional (Sáez Espligares, 2017) y posteriormente la de mármol, que fue adquirida por el Marqués de Comillas, "evitando de esta manera que fuese al extranjero, regalándola al museo arqueológico de la provincia. Este rasgo de generosidad y de amor patrio esta siendo muy elogiado. Asegurase que la referida estatua es del siglo II" (Gaceta del Sur, 12 
de Agosto de 1910, http://www.cervantesvirtual. com/nd/ark:/59851/bmcd80v0).

¿Y porque no se han sucedido las exploraciones en las aguas que rodean el islote con más frecuencia? Romero de Torres expuso:

Es de lamentar que en ella (la isla) no se hagan excavaciones de importancia y exploraciones en las aguas que la rodean, pues serían de gran interés arqueológico (...) excité a la Comisión para que recabase de las Corporaciones oficiales alguna cantidad al objeto de hacer exploraciones en la isla de Sancti Petri. (véase tomo III págs. 431-434 del B. de la R.A. de la Historia).

Y con las mismas palabras, la comisión dejo constancia:

Sr D. Enrique Romero de Torres (...) excitó a la Comisión para que recabe del Ayuntamiento y Diputación alguna cantidad para todos los años hacer exploraciones en Sancti Petri y en el mismo Cádiz cuyos resultados serían asombrosos; podría reunirse con el tiempo el Museo más rico de España con los infinitos hallazgos arqueológicos que se descubrirían, teniendo en cuenta la remota antigüedad de esta capital y su gran importancia histórica. (Extracto del Diario de Cádiz, 21 de Septiembre de 1908, Comisión provincial de Monumentos históricos y artísticos. Edición digital a partir de Boletín de la Real Academia de la Historia, Tomo 53, http://www.cervantesvirtual.com/nd/ ark:/59851/bmc6w9s4).

El problema principal, además de las aguas y la carencia de medios, sería la jurisdicción (Quintero, 1906). La isla de Santi Petri pertenecía entonces al ramo de Guerra, pasando más tarde a la Dirección General de Obras Públicas para el sostenimiento del faro. Y más lamento por parte de los eruditos, como Pelayo Quintero: "Sensible es que este monumento arqueológico no sea adquirido por el Estado y se pierda como tantos otros para España; mientras tanto nos hemos de consolar esperando que nuevos hallazgos, mostrándonos los secretos que el agua y la tierra guardan en sus profundidades, nos permitan ir poco á poco reconstituyendo la historia de la alegre isla gaditana" (Quintero, 1906: 203), quien si planteó visitas oficiales a la isla, relatando las dificultades que habían encontrado al planear dichos traslados, no en este caso por la jurisdicción del terreno, sino por el dominio de las mareas, contando con varios relatos al respecto:

En un falucho de remos tripulado por robustos pescadores, que en media hora salvaron la rompientes de la barra, pasando por la roca rompetimones y nos dejaron en seco entre las rocas del islote después de tres horas de variado viaje, que en otro tiempo se hacia en hora escasa con un buen caballo, gracias a la empedrada calzada que desde la puerta de Sancti Petri se dirigía en línea recta a la ciudad fenicia. Una vez en tierra, recorrimos las rocas que el agua dejaba al descubierto y en ellas pudimos apreciar señales indudables del antiguo camino y algunos trozos de grandes sillares, pero sin que nos fuera posible precisar época, porque los hombres, las aguas y mariscos en el transcurso de los siglos, ejerciendo su transformadora acción lo han mudado todo, haciendo necesario un detenido estudio para precisar quienes fueron los constructores de aquella calzada, teniendo que contentarnos con una rápida inspección ocular, con algunas vistas fotográficas, y con anotar nombres, que como el de arrecife del numerano parecen participar de cierto sabor. (Pelayo Quintero, Diario de Cádiz, 29 de Marzo de 1905).

Son numerosas las noticias que recoge la hemeroteca, alguna curiosa como la que relata que el célebre buzo D. Juan Escacena, que exploraba en La Caleta, donde encontró dos magníficos ejemplares de ánforas, y se trasladará a Sancti Petri, por recomendación del mismo periodista que narra los hechos, donde encontró una estatua. Recoge la peligrosidad de la zona debido a los fangos acumulados y la noticia de que es frecuente que los pescadores de Gallineras encontrasen ánforas en sus redes, localizando algunas en cantinas del barrio (Diario de Cádiz, 25 de agosto de 1905) y así como un curioso un relato de "Las tribulaciones de un dios (...) estatua mutilada y corroída" (La Dinastía, año XXI, no 7242, Viernes, 27 de abril de 1906).

La consulta a diferentes archivos a través de la 
Biblioteca Cervantes nos ha permitido acceder a cartas personales y expedientes, donde se recogen los hallazgos casuales pero también las primeras exploraciones en la zona para buscar el templo de Hércules. Podemos acceder al expediente sobre el hallazgo de restos en Sancti Petri en 1907 y lo que es mucho más interesante, la solicitud de ayuda para las exploraciones de la Real Academia de la Historia al Señor Ministro de Marina: "por lo que importaría mucho explorar pronto y hábilmente aquellos lugares donde quizá se oculten venerables restos de la antigüedad y considerando este Cuerpo literario que la Marina podría prestar eficaz cooperación en la práctica de aquellas exploraciones,... en bien de la cultura e historia patria" (Madrid, 20 de Mayo de 1907). El capitán general del Departamento de Cádiz, en referencia a estas exploraciones, reconocía que se contaba con poco material, personal especializado y créditos, precisando embarcaciones adecuadas teniendo en cuenta las condiciones de mar y corrientes (Madrid 31 de Julio de 1907, Real Academia de la Historia, http:// www.cervantesvirtual.com/nd/ark:/59851/bmcns297).

Sin duda, sería una línea de investigación muy interesante completar y analizar estos hilos de documentación, para recuperar información sobre las exploraciones, tanto si obtuvieron espectaculares resultados o simplemente aportan nuevos datos a la historiografía. Por ejemplo, nos faltaría por localizar el expediente de otro de los grandes hitos de los descubrimientos en esta zona, el hallazgo accidental, en 1925, en el bajo de Rompetimones, los restos de una estatua de bronce Thoracatha, es decir, un emperador ataviado con la vestimenta militar (Figura 8).

Conservamos varias versiones de este hallazgo que se produjo a consecuencia de los trabajos de voladura de un escollo, Rompetimones, topónimo que demuestra el peligro que suponía para navegación por tales aguas. Pelayo Quintero relataba:

La utilidad de dichas excavaciones ha quedado comprobada con el hallazgo de casi la totalidad de una estatua de grandes dimensiones, pudiendo apreciar una cantidad de trozos de plomo, extraídos por el buzo de las obras a unos dos metros de profundidad, y con ellos algunos sillares labrados (...) a unos 200 metros al saliente de las primeras piedras del islote $y$ unidos a ellas por un escollo cubierto es- casamente por tres pies de agua, lo cual permite suponer que con otros grupos de piedras, conocidos por los farallones, formaría una dársena, cuyo espigón izquierdo estaría limitado por un monumento con la estatua de Cesar.

Interpretó la fusión del plomo que se observa en los restos de la escultura como un relleno de plomo para darle consistencia ante los temporales y una posible causa de su destrucción por una chispa eléctrica (Pelayo 1926, 6 y ss.). Lo adorna una máscara del dios Oceanus, con larga melena y espesa barba que representa las olas del mar.

Antonio Sáez Espligares recoge con detalle el interés del hallazgo, que suscita algunas intervenciones autorizadas por la Dirección General de Bellas Artes, a nombre de D. Ramón de Carranza y Fernández Reguera, como alcalde presidente del Ayuntamiento de Cádiz para que practique excavaciones arqueológicas en la isla de Sancti Petri y playas adyacentes (16 de enero de 1930), que delegó en el arqueólogo y director del Museo de Cádiz, Pelayo Quintero, con presupuestos de la corporación gaditana (Sáez Espligares, 2017), con resultados infructuosos (Bernal, 2005).

Los periódicos de la época se hicieron eco de este patrimonio : “Pertenecerá, tal vez, a la famosa estatua del Hércules fenicio que según las crónicas era de bronce y a los reflejos del sol indicaba la ruta a los navegantes?" (Diario de Cádiz, 3 de Julio de 1926); noticia que también apareció en El Liberal, 4 de julio de 1926, Diario de Cádiz, 6 de Julio de 1926.

Se considera necesario completar la búsqueda de información documental en la prensa histórica, así como en la hemeroteca de la Biblioteca Virtual de Andalucía, donde se pueden localizar además de noticias relacionadas con estos primeros hallazgos, otros temas, como por ejemplo, sobre obras de infraestructura en la zona, procedencia de piedras utilizadas en construcciones, y la peligrosidad de la Barra de Sancti Petri a través de los numerosos naufragios y siniestros.

Y de nuevo un lamento en prensa, haciéndose eco de las palabras de Quintero, esta vez por la consignación económica: “ ¿No es triste que una parte de España, tan fecunda en hallazgos tan prometedora de futuros descubrimientos, se les destinen al año 3000 pesetas para excavaciones? (sobre el presupuesto para el año de las excavaciones de extramuros de Cádiz) ¿En referencia a Sancti Petri 


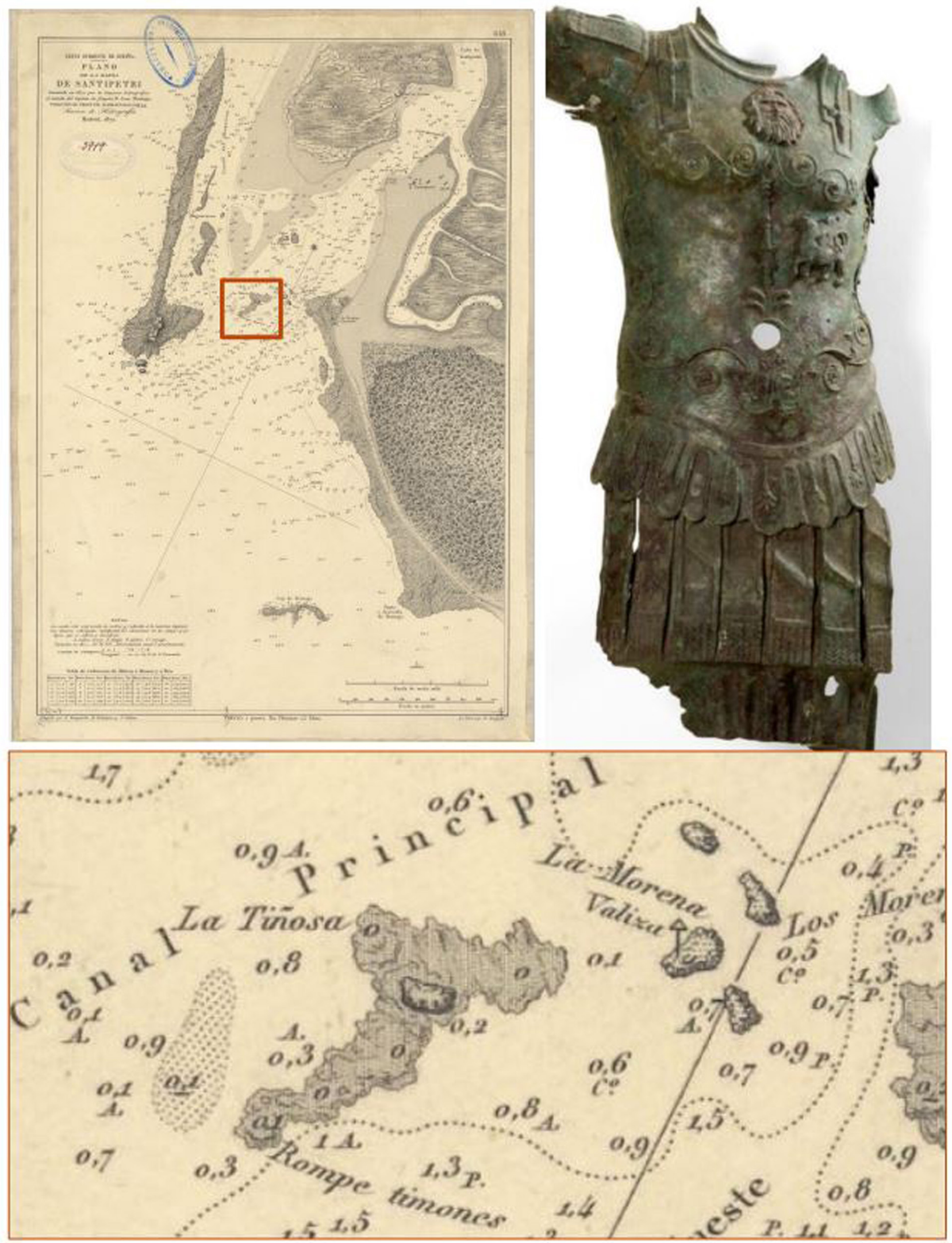

Figura 8. Detalle de situación de Rompetimones en Plano de la posición del castillo de Sancti Petri y desembocadura del canal del mismo nombre (ca. años 20 de siglo XIX). Imagen de la los restos de la escultura de bronce Thoracatha. (Fuente: Colección Pettenghi, Archivo Histórico Provincial de Cádiz). 
señala que es una lástima que se retrase por falta de protección, un hallazgo que daría mucha luz a puntos obscuros de la historia gaditana." (La Provincia, 4 de mayo de 1927, 4).

A partir de mediados del siglo pasado, hubo algunos intentos de exploraciones, con el objetivo de reconocer el lugar de hallazgo de la estatua thoracata. En 1954 hubo uno bajo la supervisión de C. Pemán y otros realizados por aficionados, concluyéndose, ante la falta de resultados, que los fuertes temporales desplazan las masas enormes de arena que lo cubren todo, encontrando fondos de arena llanos y estériles (García y Bellido, 1964: 77). Dos de ellas fueron realizadas por militares, (una por Picardo y Gener, con referencias indirectas (en Bernal, 2005: 210, escasos resultados, y otra por Gavira y Navarro, recogida por García y Bellido $(1964,76)$ quien publica un plano de situación de los hallazgos: una serie de agujeros de tres metros de diámetro y cuatro o cinco de profundidad (que aunque no descartaban que fueran naturales, señalaba la posibilidad de que fueran intencionados) y restos de una calzada que describe como losas aparejadas en hiladas, formando una especie de hongos por haber socavado el mar su base, que sitúa en el arrecife natural y que se meten en el agua.

A finales de los sesenta se intentó poner en marcha un "proyecto de intervención sistemática" a cargo del Dr. Cruz Salvadores de la Universidad de California en la zona de Sancti Petri con objeto de localizar los restos del templo (Bernal et al., 2005: 210) pero según la prensa, la intención era crear un ambicioso centro de estudios relacionado con la búsqueda la "civilización tartessiana" (véase Diario de Cádiz, 5-6 de julio de 1969), y que aunque captó la atención del Museo Arqueológico Provincial y decía tener los permisos, no llegó a hacerse efectiva.

\subsection{Intervenciones y hallazgos desde los años 70 a la actualidad}

Las primeras exploraciones científicas sistemáticas en la zona fueron dirigidas por Olga Vallespín Gómez en1973 y tenían como objetivo la elaboración de la Carta Arqueológica Submarina de la costa, centrándose en los dos principales puntos de máximo interés arqueológico a raíz de los hallazgos, la documentación escrita y oral: La Caleta y Sancti-Petri. Estas campañas que obtuvieron importantes resultados publicados en congresos, jornadas (II Encuentro de Arqueología e Historia de San Fernando, entre otras) y revistas especializadas de la época (Vallespín, 1985, 1996), que solo nombramos pues serán objeto de un artículo en esta misma publicación.

En 1985 se realizó una intervención en el islote con sondeos, localizando algunas estratigrafías parciales en dos de ellos (Corzo, 1992: 39), una inhumación tardorromana o medieval en el primero y en el segundo una estratigrafía con siete niveles antrópicos sobre las características arcillas rojas terciarias (s. VIII/VII a.C. - I a.C.), que se ha interpretado como periferia del recinto sacro, que estaría ubicado en la zona hoy cubierta por el mar situada entre el islote y la Punta del Boquerón (Bernal et al., 2005: 209-210).

En 1984 se produjeron unos hallazgos excepcionales, que suponían la constatación de las fuentes clásicas sobre la antigüedad de la zona: un conjunto de figuras de bronce, de carácter religioso -ya sean exvotos o imágenes de culto-, de la época de la colonización fenicia (siglos VIII y VII a.C.), frecuentes en el Mediterráneo (Prados et al., 2018: 395).

La extracción de arenas en el Caño de Sancti Petri ha sido muy frecuente en la zona, no solo para recuperar calado, sino también para utilizar los sedimentos para otros fines, como la construcción o en viveros de moluscos, etc. En una de estas dragas se recuperaron un grupo de estas estatuillas de bronce que fueron entregadas por sus descubridores a la Delegación de Cultura de la Junta de Andalucía. Recogemos las noticia detallando el orden de aparición de estos bronces del tipo Smiting God (Bernal et al., 2005: 210-211; Sáez et al., 2005: 875 y 877) (Figura 9).

Pedro Rodríguez Castillo, propietario del barco Teo II entregó las dos primeras al Ayuntamiento de San Fernando (recientemente nos ha puntualizado que fueron recuperadas por los hermanos Rodríguez Pérez, a saber, Pedro, Juan Horacio, José Agustín y Nicolás, en el barco propiedad de su padre, Juan Rodríguez, y su socio José Castillo) y que el alcalde donó al Museo Provincial. El tercer exvoto fue entregado poco después por los propietarios de otra de la dragas areneras que estaban actuando en la zona de la desembocadura del caño (Bernal, 2005) al Museo provincial, donde fue restaurada, aunque presentó una reactivación del proceso corrosivo, característico de los bronces arqueológicos que han permanecido en ambientes salinos, por lo que necesitó una segunda intervención de estabilización realizada en Centro Andaluz de Arqueología 

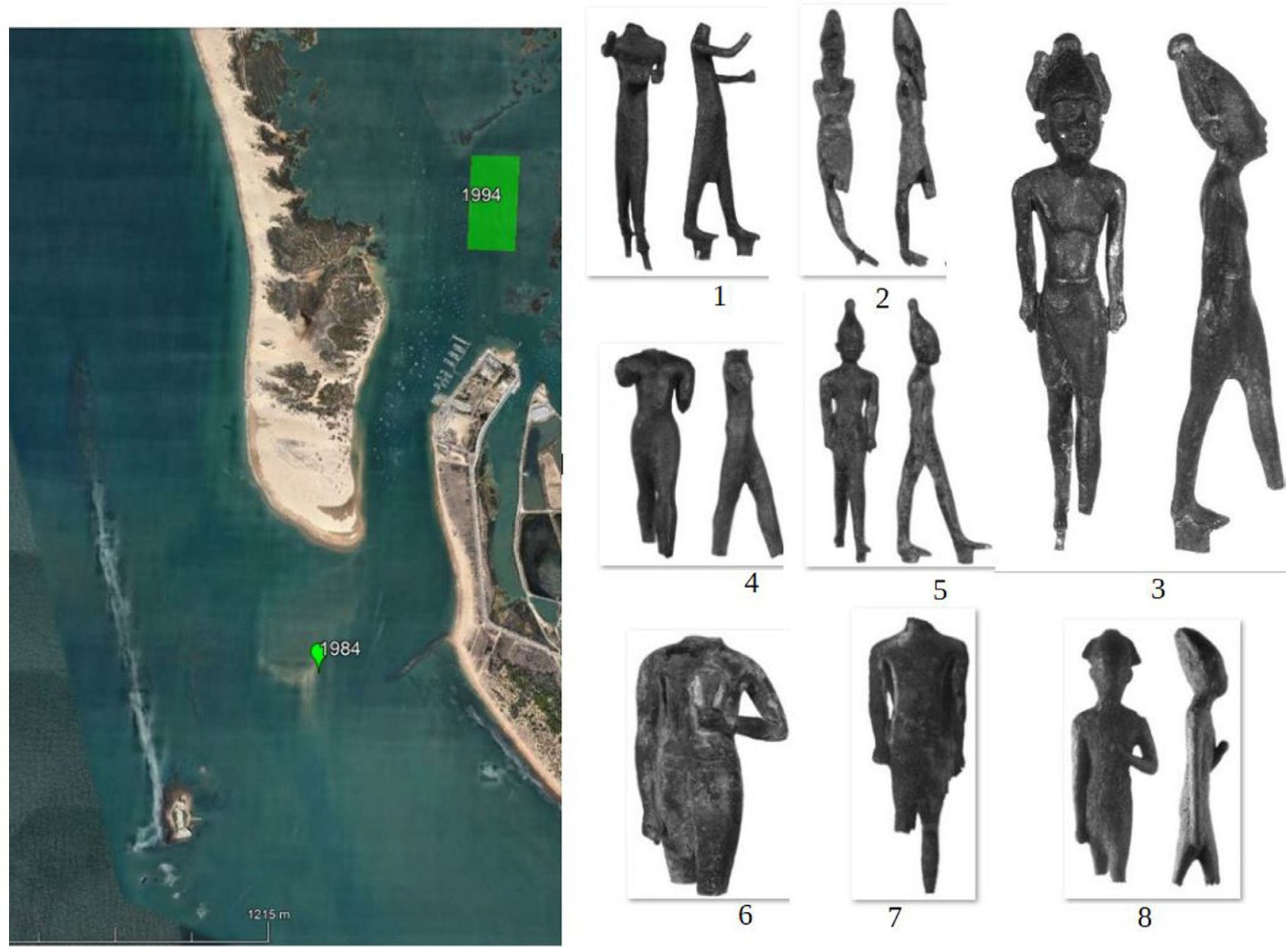

Figura 9. 1. Situación delimitada en los años ochenta. (Fuente: Corzo, 2005; Perdigones, 1991) y en polígono área de proyecto en 1994 sobre imagen de Google Earth; 2-8. Bronces hallados entre 1984 y 1990. (Montaje: A. Higueras).

Subacuática del IAPH (Revista PH 33, 2000: 15).

Los hallazgos no fueron simultáneos. Entre 1985 y 1987, dos estatuas mas fueron entregadas al museo gaditano en las mismas condiciones que las anteriores (Perdigones, 1991, figs. 5 y 6) y procedentes de la misma zona, aunque con varias versiones, sobre su origen, como la criba de arenas extraídas de Sancti Petri (Bernal, 2005: 211; Perdigones, 1991: 1123) o su compra en mercadillo. En 1990, la figurilla sexta fue donada al recién creado Museo Histórico Municipal por A. López Muñoz (Bernal, 2005: 211; Jiménez, 2014: 769, fig. 3). La numero siete fue donada por Antonio Rodríguez. Desde entonces han circulado rumores sobre la existencia de más piezas en el mercado negro de antigüedades, comprobándose que estos materiales circulan en plataformas de subastas (como es el caso de la recuperada en Huelva, procedente de un contexto terrestre, en Prados et al., 2018: 386), fijándose hasta el momento un total de ocho en la zona de Sancti Petri (Corzo, 2005: 93).

El hecho de que fueran localizadas en un contexto subacuático no descarta que procedan de un yacimiento terrestre, habida cuenta de la cantidad de hallazgos sumergidos en esta zona de los que ya hemos hablado, y que se corresponderían a yacimientos que el mar ha arrasado, ya sean del templo o de sus alrededores (Prados et al., 2018: 403). Las explicaciones sobre este contexto perdido han sido variadas, desde fluctuaciones de la paleocosta, una favissa situada en el interior o en los alrededores del santuario (Corzo, 2005: 93), ofrendas arrojadas al agua, pero podrían darse otras, tales como un depósito del fundidor, objetos escondidos ante una amenaza, bienes perdidos o arrasados tras un evento de alta energía, etc.

En un principio se delimitó la zona de dragado entre Rompetimones y la lengua de arenas que cubre la zona (Figura 9), estando los areneros reacios a concretar la ubicación exacta, porque según 
cuentan, se prohibía continuar con la extracción de arena quedando a espera durante mucho tiempo para que les adjudicaran un nuevo tramo libre de restricciones, por lo que siempre tenían sus "cuitas" a la hora de declarar hallazgos (Diario de Cádiz, 1990). Lo cierto es que no se llevó a cabo ninguna prospección ni excavación para determinar la naturaleza del hallazgo en aquel primer momento (Gallardo y Martí, 1998: 41-46).

Entre 1993-1996 se desarrolló el Proyecto de Investigación de la Bahía de Cádiz, bajo la codirección de Gallardo, García Rivera, Alonso, Martí Solano, Ramírez Delgado y Sáenz Gómez, con el objetivo de completar la Carta Arqueológica Subacuática (Figura 8).

Además de recopilar documentación histórica y oral de yacimientos con los que seleccionaron los puntos de interés, uno de los objetivos principales de la primera campaña fue la formación en técnicas de buceo y arqueología subacuática de un equipo de recién licenciados. Después de realizar el curso de buceo deportivo, Sancti-Petri fue el lugar elegido como "aula de práctica" para que los alumnos aplicasen la metodología, comenzando con los diferentes sistemas de prospección, seleccionándose para ello zonas con características favorables a los intereses perseguidos, en relación a la profundidad y a las corrientes, eligiendo áreas en torno al Islote y al caño de Sancti Petri, donde se presuponía la existencia de restos arqueológicos.

La segunda campaña, en 1994, sufrió una modificación de objetivos, debido al hallazgo casual de materiales arqueológicos por parte de miembros de Protección Civil (Diario de Cádiz, 1 de julio de 1994) en la zona de Lavaculos (área media de la desembocadura del caño) por lo que se planteó una prospección superficial, con recogida sistemática de 365 piezas. Se trataba de una zona con gran acumulación de material cerámico, apenas fragmentado, con cronología centrada principalmente en tres períodos: s. I-II d.C.; s. IV-V d.C. y s. XI-XII d.C. La zona es un área muy problemática para el buceo debido a la escasa visibilidad, pero sobre todo a las fuertes corrientes de marea e intenso tráfico marítimo de carácter deportivo. El buen estado de conservación de las numerosas piezas documentadas indicarían que podría tratarse de un yacimiento in situ y no de una acumulación de restos cerámicos producida por las corrientes (Gallardo, 1994, 1995, 2001). Los yacimientos localizados fueron declarados ZA bajo la denominación de "Desembocadura del Caño de Santi-Petri" (BOJA no 129 de 06/07/2009).

Se planteó en 1994 una intervención en la entrada al Caño Carboneros, zona que delimitaron los areneros tras retomar el contacto con ellos debidos a los trabajos desarrollados en la zona (Gallardo et al., 1998: 44-48), donde según ellos describían se apreciaba un fondo plano que presentaba resistencia a la cuchara de la draga, y que les parecía no era sustrato natural. Se acotó un área concreta, retirando con una draga, "La Salinera", la primera capa de arenas acumuladas en los últimos años. Se aplicaron técnicas geofísicas, con el uso de un perfilador de la casa ORE de 3,5 $\mathrm{kHz}$, y de hasta $10 \mathrm{~kW}$ de potencia, que permitieron detectar una serie de pequeñas anomalías, en general discontinuas e incluso puntuales, entre 0,5 y $2 \mathrm{~m}$ de profundidad, y algunas a $3 \mathrm{~m}$. Se realizaron prospecciones visuales utilizando cabos de $25 \mathrm{~m}$ separados entre sí un metro y medio, picas y detector de metales (Gallardo y Martí, 1994). La campaña se realizó en pleno invierno y contó con los vientos del norte, que aclararon las turbias aguas del caño. A pesar de eso, no se localizó ningún hallazgo relacionado con las estatuillas, puesto que bajo una primera capa de material de poca consistencia (arena o fango), aparecía un estrato arcilloso muy compactado y de gran dureza, que inducía a error, puesto que podía confundirse con el nivel duro y liso al que hacían referencia los areneros (Gallardo y Martí, 1994: 41).

Esta zona ha sido objeto de un estudio morfosendimentario sobre depósitos de alta energía (Gutiérrez et al., 2015: 106; Proyecto GL201016878 del Ministerio de Ciencia e Innovación, España/FEDER, Departamento de Ciencias de la Tierra, Universidad de Cádiz y Departamento de Geología, Universidad de Huelva) en el que se han aplicando diversas herramientas geofísicas, entre ellas un sonar C-MAX 2000. A través del análisis morfológico han descubierto una gran variabilidad en los campos de formas de fondo, diferenciando hasta cinco campos de dunas, en un estado de equilibrio-desequilibrio, detectado que la marea es la principal responsable de la configuración del fondo del caño a partir de una dinámica de sedimentos muy activa. Esto supone que estos fondos están sujetos a procesos de tapado-destapado, variando según la fuerza de las mareas (Figura 10). A este estudio le deberían seguir líneas de trabajo muy interesantes, un completo estudio multidisciplinar, geomorfológico y arqueológico, en el que se busque respuestas a la génesis y evolución 
de los yacimientos arqueológicos localizados en el fondo del caño, fondeaderos, pecios, sin descartar que algunas zonas puedan corresponder a yacimientos terrestres que han sido arrasados por el agua debido a alteraciones en la línea de costa, debido a factores naturales o antrópicos, incluyendo la modificaciones como la construcción del puerto deportivo y del espigón de la Punta de las Piedras, que provocan sin duda transformaciones en el régimen hidrodinámico, que podrían generar canales encauzados de corrientes, que en algunos casos pueden descubrir yacimientos que permanecían soterrados.

\section{La Isla en la Carta Arqueológica Subacuáti- ca. Prevenir y Proteger: ¿Qué conocemos?}

Si la Carta Náutica es un instrumento de descripción y representación del territorio sobre el que se pretende navegar evitando los escollos, la Carta Arqueológica Subacuática es el documento que señala, además de la situación de los yacimientos, los peligros en el camino de la tutela del PAS y las enfilaciones para su correcta protección. No es un fin en sí misma, es la "información sobre la que se sustentan el establecimiento de mecanismos de protección y el diseño de estrategias de investigación" (García y Alzaga, 2008: 129), entendiéndola como un instrumento que se utilizará de referencia para identificar, evaluar y diagnosticar este patrimonio y con el que se programará, no solo su protección, conservación e investigación, como se ha señalado, sino también su difusión y puesta en valor (Rodríguez et al., 2002: 29).

La Carta Arqueológica Municipal de San Fernando, coordinada por Bernal, Sáez Espligares, Sáez Romero, Díaz Rodríguez, Lorenzo Martínez y Toledo Coello, constituyó un trabajo excepcional de recopilación del patrimonio arqueológico del término, incluyendo por primera vez el patrimonio subacuático. Se incluyen dentro de este nivel de protección 3, aquellas "zonas de las que se poseen datos científicos que presuponen su notable importancia y la probabilidad de que una vez realizada la excavación arqueológica, los restos descubiertos puedan ser conservados integral o parcialmente bajo cimentación áreas en las que no sería factible inicialmente la puesta en valor de elementos, según los datos aportados por ejemplos próximos, pero sí se debe proceder a su conservación como hito histórico significativo o de conservación obligada" (Bernal et al., 2005: 459-460), incluyendo en este nivel los yacimientos subacuáticos catalogados:

- Caño de Sancti Petri (no 15).

- Entorno subacuático del Castillo de Sancti Petri (no 27).

- Playa de Camposoto - Playa del Castillo (no 47).

Recoge como afección principal sobre estos yacimientos, la ocasionada por agentes marinos y proponiendo el control arqueológico condicionado a la aparición de restos arqueológicos (Bernal
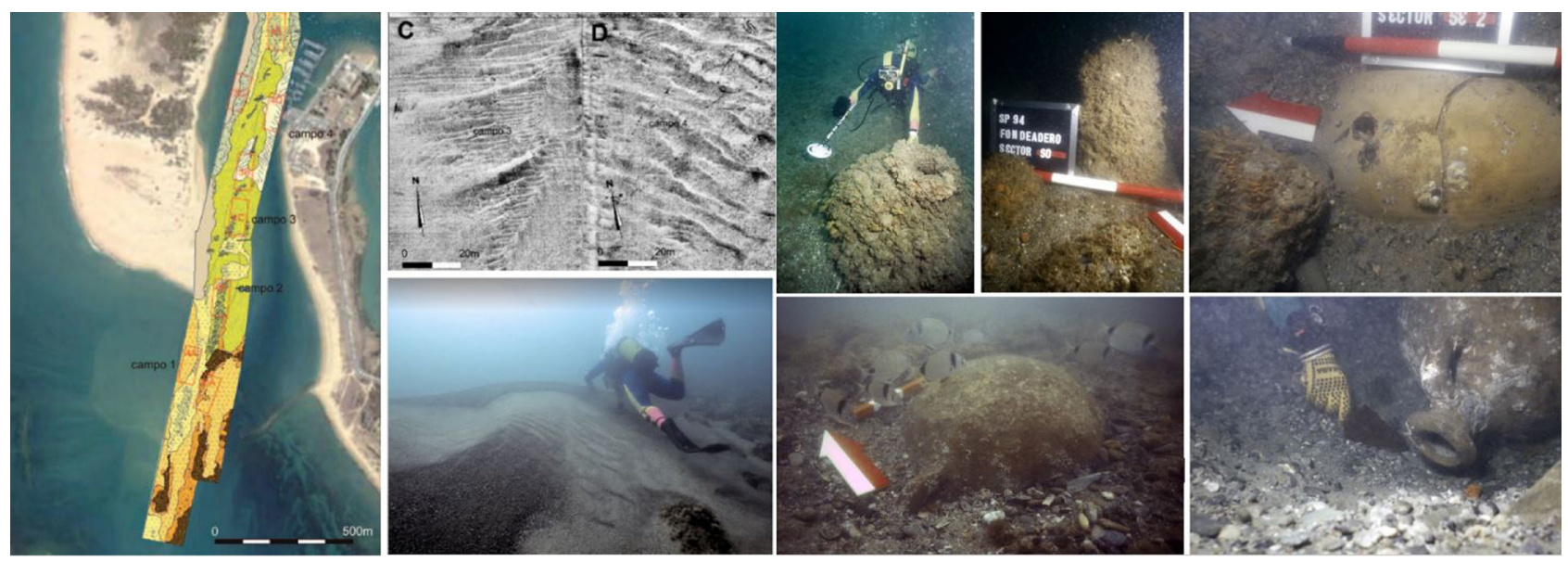

Figura 10. 1. Izquierda campos de formas del fondo en la zona de desembocadura; 2. En recuadro C se muestran los registros sonográficos del Campo 3 formado por dunas grandes y dunas medianas sobreimpuestas. (Fuente: Gutiérrez, 2015). Las imágenes subacuáticas se corresponden con las prospecciones realizadas en esta zona durante el Proyecto de Investigación 1992-1996, en el yacimiento declarado

Zona Arqueológica Desembocadura del Caño de Sancti Petri. (Fuente: Archivo gráfico IAPH). 
et al., 2005: 469). Este condicionante debería ser eliminado de la publicación de referencia en futuras ediciones, ya que se trata de yacimientos en los que sus antecedentes arqueológicos justifican la realización de cautelas previas a cualquier proyecto de obra. Se trata con ello, de dar una respuesta adecuada al posible impacto negativo que las actividades legítimas puedan ocasionar tanto en el patrimonio conocido como sobre el que aún no ha sido localizado, estableciendo los mecanismos adecuados para su correcta protección e investigación. El no establecimiento de las cautelas arqueológicas oportunas podría provocar una incidencia negativa sobre el mismo, con diverso grado de afección.

El CAS-IAPH viene completando desde sus inicios en 1998 un proyecto abierto, una línea de trabajo permanente, como es la redacción y actualización de la Carta Arqueológica Subacuática, encaminada a la investigación, protección, conservación y difusión del PAS de la Comunidad Autónoma de Andalucía, y una vez conocidos e identificados, su protección jurídica (García y Alzaga, 2008: 141).

Las ZA inscritas en el Catálogo General del Patrimonio Histórico Andaluz como Bienes de Interés Cultural, frente a las aguas del término municipal de San Fernando, hasta el momento, son las siguientes: Yacimientos Subacuáticos de La Carraca, Pecio de Camposoto, Pecio del Cobre, Sillares del Castillo de Sancti Petri, Cañones del Arrecife de Sancti Petri y Desembocadura del Caño de Sancti Petri (Decreto 285/2009, de 23 de junio, en Boja no 129 de 6 de julio de 2009). Del mismo modo, la declaración de Zona de Servidumbre Arqueológica (ZSA) "Espacio Subacuático Bahía de Cádiz" (Orden de 20 de abril de 2009, en Boja no 101 de 28 de mayo de 2009), incluye además del litoral, caños, marismas y playas, al cerrar el polígono de protección en la línea del Dominio Público Marítimo Terrestre (DPMT), esto es, hasta el sitio donde se haga sensible el efecto de las mareas (art. 3, 1.a de la ley 22/1988, de 28 de julio de Costas).

Desde el área de Intervención del CAS-IAPH se ha trabajado para establecer protocolos de acción que disminuyan el impacto ocasionado por las obras de infraestructura litoral, generalmente dragados, construcción de diques y muelles, estaciones de aguas residuales, regeneraciones de playas, etc., para evitar la posible afección que podrían causar los trabajos proyectados, desde la distorsión perceptual con la ocultación o imposibilidad de acceso a yacimientos, el destape debido a cambios en la dinámica litoral a consecuencia de nuevas construcciones, alteraciones del sustrato, aumento de presiones, hasta su posible destrucción.

Señalamos algunas zonas con las actuaciones realizadas, principalmente proyectos de infraestructura: Caño de Sancti Petri (extracciones de arenas, balizamiento, Plan de Utilización, atraque embarcaciones menores, Plan de Usos); Torregorda (Emisarios, Estudio de caracterización); La Carraca (dragados, muelles); Gallineras (Atraques, Plan de Utilización), Puente de Hierro (Ampliación de pantalán y dragado), La Casería (Dragado), etc. Tras el análisis de cada uno de los proyectos y las características técnicas de los mismos, y sobre todo en función de las zonas afectadas, la administración competente procederá al establecimiento de las cautelas arqueológicas oportunas, con el objeto de minimizar su posible impacto.

El análisis de estos proyectos pasa por revisar cada una de las bases de datos del Centro:

- DOCUSUB, donde es posible realizar búsquedas de naufragios históricos de Andalucía con los diferentes criterios de zonificación. En este caso, la consulta con las siguientes zonas, el "Frente de Cádiz y Bahía de Cádiz Interna, entorno T.M. de San Fernando y Caños de la Carraca (T.M. Puerto Real)" (incluimos algunos de Sancti Petri) genera referencias a 31 naufragios, algunos documentados tras la revisión de los Partes de Vigía, entre ellos:

- Urca Desembocadura del rio de Sancti Petri (1625), de nacionalidad francesa.

- San Hermenegildo (1673), San Espiridion (1758), fragata El Intrépido (1779) en Sancti Petri.

- Navío de línea Fougeaux, entre Santi Petri y Torregorda (1805) a causa de un temporal tras la Batalla de Trafalgar.

- Místico perdido en la playa entre Torregorda y Sancti-Petri el 21 de septiembre de 1813 (Diario Marítimo de la Vigía de 1813).

- Bergantín sueco Utile, naufragado el 25 de agosto de 1827 en las Piedras del Castillo de Sancti-Petri (№ 35 semanal del 27 agosto/2 septiembre de 1827).

- Goleta de guerra a pique en el caño de la Carraca (martes 18 de noviembre de 1862).

- YACSUB: base de datos que recoge las noti- 
cias orales que hacen referencia a posibles yacimientos subacuáticos, desde artillería (informaciones relacionadas con el armamento del Fougueux, además de otras piezas en entre Sancti Petri y Camposoto), dos pecios, concentraciones de restos en la Punta del Boquerón, en los Farallones y zonas de fondeo, siendo todas ellas noticias por confirmar.

- SIGNAUTA: proporciona una herramienta para el estudio de la zona, uniendo a través de programas SIG, información sobre medio físico,evolución geomorfológica de la costa, variables como la batimetría, la composición de los fondos, toponimia, naufragios, información oral, siniestros marítimos, obra pública, ordenamiento jurídico administrativo, además de la cartografía histórica (Alonso et al., 2007).

Toda esta información de nuevos yacimientos completan la Carta Arqueológica Subacuática, para su incorporación a MOSAICO, el Sistema de Gestión e Información de los Bienes Culturales de
Andalucía (anteriormente ARQUEOS y SIPHA) que desde 2009 integra, en una única herramienta, las actuaciones necesarias para la gestión y documentación de los bienes culturales llevadas a cabo en el ámbito de la Secretaría General de Cultura por parte de la Dirección General de Bienes Culturales y Museos, el Instituto Andaluz del Patrimonio Histórico y las Delegaciones Territoriales de Cultura y Patrimonio Histórico.

\section{Conclusiones. Sobre los trabajos pendientes}

La documentación histórica, fuentes escritas, cartográficas y arqueológicas del entorno de la isla de Sancti-Petri son excepcionales. En estas páginas solo se presenta una breve aproximación a la historiografía de los hallazgos arqueológicos en la zona. Dada la multiplicidad de los temas que quedan por tratar, instamos a las instituciones a elaborar una publicación monográfica específica que atienda a esta particular situación (Figura 11).

A continuación apuntamos algunas líneas de investigación, de naturaleza muy variada, que po-

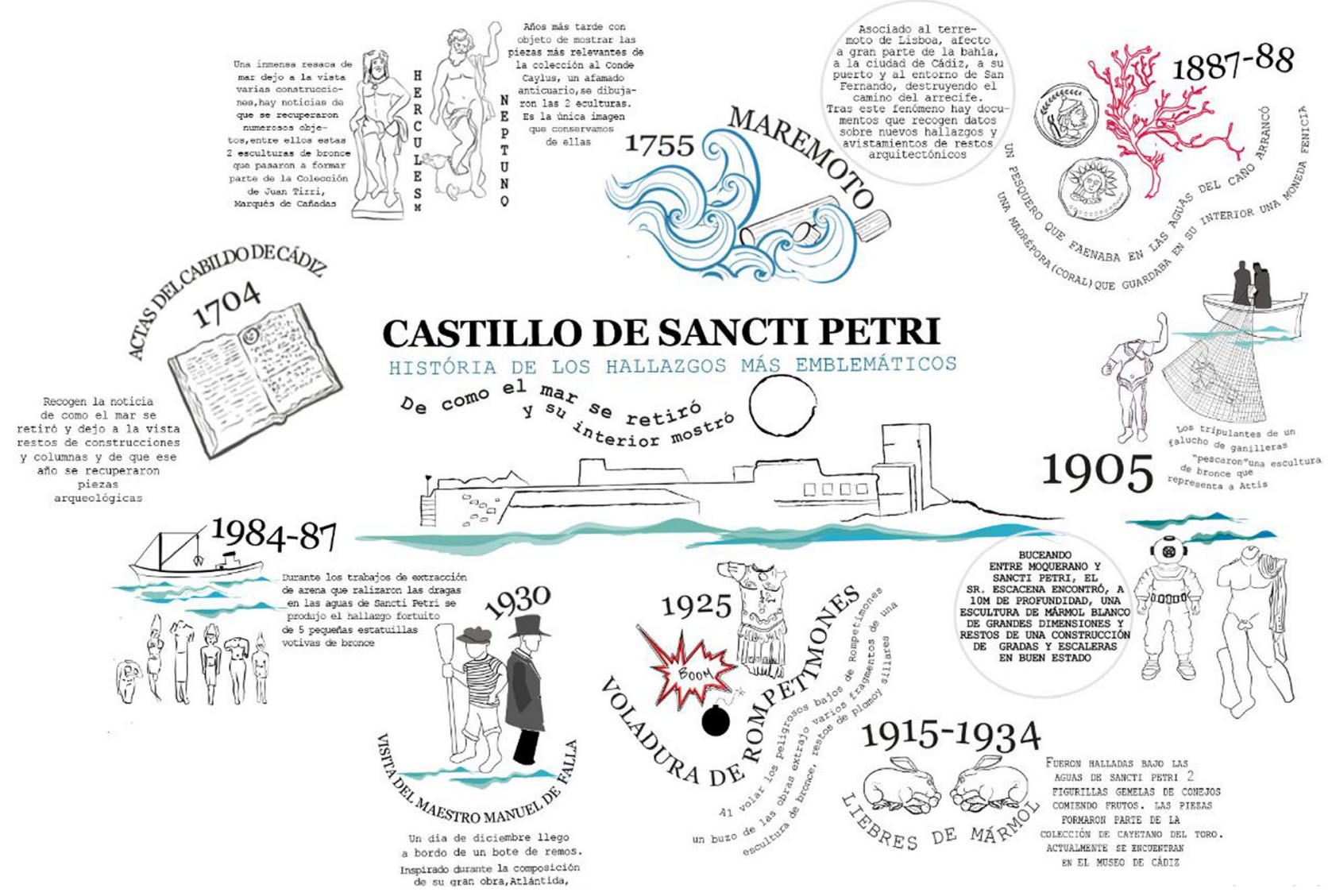

Figura 11. Propuesta de cartilla de difusión. Acercar el patrimonio a la sociedad es fundamental para que lo conozca, valore y proteja. Propuesta didáctica Arte, Ciencia y Creatividad (Fuente: Inés Vallespín). 
drían ser objeto de estudios futuros:

- Investigación multidisciplinar sobre la problemática de la evolución geomorfológica e histórica de la desembocadura del caño de Sancti Petri.

- Elaborar estudios de la vulnerabilidad del patrimonio costero y su afección por el cambio climático en este territorio tan susceptible a la inundación y a la continua erosión marina, aplicando al análisis herramientas SIG.

- Retomar los proyectos de investigación multidisciplinar en la zona, no solo con prospecciones geofísicas y tradicionales, sino con las inmersiones en archivos que aporten nuevas fuentes documentales, cartográficas y bibliográficas sobre la historiografía de la zona. El objetivo de estas investigaciones no es el de de responder a las múltiples cuestiones pendientes, sino sobre todo, ya que a través de los resultados obtenidos plantear la correcta delimitación de los yacimientos, de cara a su investigación y a valorar las medidas de protección más adecuadas.

- Difundir de este rico legado, la gran asignatura pendiente, que hay que dar a conocer y enseñar a valorar, claves para que la ciudadanía se implique y se sumerja en la necesaria dinámica de protección.

\section{Bibliografía}

ABASCAL PALAZÓN, Juan Manuel. 2000: Fidel Fita (1835-1918). Su legado documental en la Real Academia de la Historia. Gabinete de Antigüedades de la Real Academia de la Historia. Historia, I. Antigüedades, 1. Real Academia de la Historia. Madrid.

ABELLÁN PÉREZ, Juan. 1996: El Cádiz islámico a través de sus textos. Universidad de Cádiz. Cádiz.

ALONSO VILLALOBOS, Carlos. 2011: "Los documentos cartográficos como fuente de información para el conocimiento del patrimonio cultural marítimo y fluvial". Revista PH: Boletín del Instituto Andaluz del Patrimonio Histórico, La Cartografía: entre el documento histórico y la gestión del patrimonio, 19, № Extra 77, pp. 82-84.

ALONSO VILLALOBOS, Carlos; BENÍTEZ LÓPEZ, David; MÁRQUEZ CARMONA, Lourdes; VALIENTE ROMERO, Antonio; RAMOS MIGUÉLEZ, Silvia; MARTÍNEZ DEL POZO, José Ángel. 2007: “SIG-
Nauta: un sistema para la información y gestión del patrimonio arqueológico subacuático de Andalucía". Boletín del Instituto Andaluz del Patrimonio Histórico, no 63, pp. 26-41.

ALONSO VILLALOBOS, Carlos; GRACIA PRIETO, F. Javier; MÉNANTEAU, Loïc. 2003: “Las salinas de la Bahía de Cádiz durante la Antigüedad: Visión geoarqueológica de un problema histórico". Spal, 12, pp. 317-332.

ALONSO VILLALOBOS, Carlos; GRACIA PRIETO, F. Javier; BENAVENTE GONZÁLEZ, Javier. 2004: "Las marismas, alfares y salinas como indicadores para la restitución paleotopográfica de la Bahía de Cádiz durante la Antigüedad". En: XVI Encuentros de Historia y Arqueología: las industrias alfareras y conserveras fenicio-púnicas de la Bahía de Cádiz (San Fernando 2000), pp. 263-287. Fundación Cajasur. Córdoba.

ALONSO VILLALOBOS, Carlos ; GRACIA PRIETO, F. Javier; BENAVENTE GONZÁLEZ, Javier. 2009: "Evolución histórica de la línea de costa en el sector meridional de la Bahía de Cádiz". Revista Atlántica-Mediterránea de Prehistoria y Arqueología Social, 11, pp.13-37.

ALONSO VILLALOBOS, Carlos; GRACIA PRIETO, F. Javier; RODRÍGUEZ-POLO, Silvia.; MARTÍN PUERTAS, Celia. 2015. "El registro de eventos energéticos marinos en la bahía de Cádiz durante épocas históricas". Cuaternario y Geomorfología, 29 (1-2), pp. 95-117.

ALONSO VILLLOBOS, Carlos; MÉNANTEAU, LoÏc; NAVARRO DOMÍNGUEZ, María; MILLE, Sara; GRACIA PRIETO, F. Javier. 2001: "Antropización histórica en un espacio natural. Las salinas de la Bahía de Cádiz". Revista PH, Boletín del Instituto Andaluz del Patrimonio Histórico, 35, pp. 172-185.

ALZAGA GARCÍA, Milagros; GUERRERO LÓPEZ, Cristina; HIGUERAS-MILENA, Aurora; MARTÍ SOLANO, Josefa; RODRÍGUEZ MARISCAL, Nuria. 2012: "Investigación y protección del patrimonio Arqueológico Subacuático localizado en el litoral de la provincia de Cádiz". En J. M. BARRAGÁN (coord.): I Congreso Iberoamericano de Gestión Integrada de Áreas Litorales, pp 319-332. Grupo de Investigación Gestión Integrada de Áreas Litorales Universidad de Cádiz. Cádiz.

ARTEAGA, Owaldo; SCHULZ, Horst; ROOS, A. María. 2008: "Geoarqueología Dialéctica en la Bahía de Cádiz". Revista Atlántica-Mediterránea de Prehistoria y Arqueología Social, 10, pp 
21-116.

BERNAL-CASASOLA, Dario; SÁEZ ESPLIGARES, Antonio; SÁEZ ROMERO, Antonio M.; DÍAZ RODRÍGUEZ, José Juan; LORENZO MARTÍNEZ, Lourdes; TOLEDO CUELLO, Francisco J. 2005a: La Carta Arqueológica Municipal de San Fernando (Cádiz). Consejería de Cultura de la Junta de Andalucía. Sevilla.

BERNAL-CASASOLA, Dario; SÁEZ ESPLIGARES, Antonio; MONTERO FERNÁNDEZ, Roberto; DÍAZ RODRÍGUEZ, José Juan; SÁEZ ROMERO, Antonio M.; MORENO, Diego; TOBOSO SUÁREZ, Ernesto. 2005b: "Instalaciones fluvio-marítimas con drenaje ánforas romanas: a propósito del embarcadero flavio del caño de Sancti-Petri (San Fernando, Cádiz)". SPAL, 14, pp. 179-230.

BETHENCOURT, Manuel; GRACIA PRIETO, F. Javier; DEL RÍO, Laura; BENAVENTE GONZÁLEZ, Javier. 2011: "Los restos de naufragios históricos como indicadores del paleolíneas de costa. El caso del Fougueux (Bahía de Cádiz)”. En I. MONTOYA, I. RODRÍGUEZ y M. J. SÁNCHEZ (eds.): Avances en Geomorfología Litoral Actas VI Jornadas de Geoarqueología litoral, pp. 4750. Tarragona.

BLANCO FREJEIRO, Antonio. 1985: "Los nuevos bronces de Sancti Petri". Boletín de la Real Academia de la Historia, CLXXXII, 2, pp. 207-216.

BLÁZQUEZ MARTÍNEZ, José Mà. 1954: "El Herakleion Gaditano, un templo semita en occidente". I Congreso Arqueológico del Marruecos español 1953, pp. 309-318,.Tetuán.

BLÁZQUEZ MARTÍNEZ, José Mạ. 2001: "El Herakleion gaditano y sus ingresos". En L. HERNÁNDEZ, L. SAGREDO y J. M. SOLANA (eds.): Actas del I Congreso Internacional de Historia Antigua. La Península Ibérica hace 2000 años, pp. 599-606. Universidad de Valladolid. Valladolid.

BLOT B.H. PINHEIRO, Mํㅡㄴ Luisa. 2003: "Os portos na origen dos centros urbanos. Contributo para a arqueología das cidades marítimas e flúvio-marítimas em Portugal". Trábalos de Arqueología, 28, pp 1-35.

BRUQUETAS GALAN, Carlos. 2013: Acercamiento al Sector Torre Gorda Sancti Petri. Elementos para un reconocimiento arqueológico. Trabajo de fin de máster. Universidad de Cádiz.

CASTILLO BELINCHÓN, Rocío. 2014: "La Arqueología como ciencia de investigación histórica para la protección y difusión del Patrimonio Cultural Subacuático [en línea]". En La fraga- ta Nuestra Señora de las Mercedes. Patrimonio subacuático recuperado. http://www.culturaydeporte.gob.es/fragatamercedes/dam/ jcr:02a37672-bc2b-4731-81ae-11a1f119e8fa/arqueologia-ciencia.pdf.

CAYLUS, Anne Claude Philippe. 1767: Recuil d'antiquités egyptiennes, etrusques, grecques, romaines et gauloises. Suplemento del tomo 7, lamina XCVII. Bibliothèque de l'Institut National d'Histoire de l'Art. París. https://bibliotheque-numerique.inha. $\mathrm{fr} /$ viewer $/ 5666 /$ ? offset $=7$ \#page $=462 \&-$ viewer $=$ picture $\& 0=$ bookmark $\& n=0 \& q=$.

CORZO SÁNCHEZ, Ramón. 1992: "El templo de Hércules gaditano en época romana". Boletín Museo de Cádiz, V, pp.37-47,.

CORZO SÁNCHEZ, Ramón. 2005: “Sobre las primeras imágenes y la personalidad originaria de Hercules Gaditanus". SPAL, 14, pp. 91-122.

CHÍAS NAVARRO, Pilar; ABAD BALBOA, Tomás. 2011: El Patrimonio fortificado. Cádiz y el Caribe: una relación trasatlántica. Servicio de Publicaciones de la Universidad de Alcalá.

DE MORALES, Antonio. 1575: Antigüedades de las ciudades de España. http://bibliotecadigital. jcyl.es/es/consulta/registro.cmd?id=8423.

DOMÍNGUEZ-BELLA, Salvador. 2008: “Geología en el entorno de la ciudad de Cádiz. Revista Atlántica-Mediterránea de Prehistoria y Arqueología Social, 10(1), pp 117-130.

FLÓREZ, Enrique. 1702-1773: España sagrada: theatro geographico-historico de la iglesia de España, Tomo X. Madrid.

GANDUL HERVÁS, Alejandro. 2006: "El naufragio en 1738 del navio Sverige en la costa de Cádiz o la Historia que no fue". Revista General de Marina, 251,pp. 433-448.

GANDUL HERVÁS, Alejandro. 2018: El naufragio del Navio Sveridge Trabajos de recuperación y conflicto diplomático, 1738-1764. Ediciones Náuticas

GALLARDO ABÁRZUZA, Mercedes; GARCÍA RIVERA, Carmen; ALONSO VILLALOBOS, Carlos; MART SOLANOÍ, Josefa; RAMÍREZ DELGADO, Juan Ramón; SAENZ GÓMEZ, Miguel Ángel. 1992: "Prospección arqueológica subacuática en Sancti Petri". Anuario Arqueológico de Andalucía, pp 80-81.

GALLARDO ABÁRZUZA, Mercedes; MARTÍ SOLANO, Josefa; ALONSO VILLALOBOS, Carlos; GARCÍA RIVERA, Carmen. 1995: "Carta arqueológica subacuática de la Bahía de Cádiz". 
Cuadernos de Arqueología Marítima, 3, pp. 105-122.

GALLARDO ABÁRZUZA, Mercedes; MARTÍ SOLANO, Josefa; ALONSO VILLALOBOS, Carlos; GARCÍA RIVERA, Carmen. 1998: "Prospecciones arqueológicas subacuáticas en Sancti-Petri”. Anuario Arqueológico de Andalucía. Tomo II, p. 44-48.

GALLARDO ABÁRZUZA, Mercedes; MARTÍ SOLANO, Josefa; ALONSO VILLALOBOS, Carlos; GARCÍA RIVERA, Carmen. 2000: "Prospecciones arqueológicas subacuáticas en Sancti-Petri. Proyecto general de investigación de la Bahía de Cádiz". Anuario Arqueológico de Andalucía. Tomo II, pp. 15-25.

GARCÍA Y BELLIDO, Antonio. 1944: "Hallazgos romanos de Ronda, Carmona, Norte de África, Sancti Petri y Cádiz, según una relación del siglo XVIII". Archivo Español de Arqueología, 57, pp. 363.

GARCÍA Y BELLIDO, Antonio. 1963: "Hércules Gaditano". AEspA, XXXVI.

GARCÍA Y BELLIDO, Antonio. 1964: "Hallazgos arqueológicos en Sancti-Petri”. Revista General de Marina, Tomo167, pp 73-78.

GARCÍA RIVERA, Carmen; ALZAGA GARCÍA, Milagros (2008): "La Carta Arqueológica Subacuática de Andalucía como instrumento para la tutela de un patrimonio emergente". Mainake, XXX, pp. 129-143.

GÓMEZ TOSCANO, Francisco; ARRUDA, Ana Margarida; RODRÍGUEZ-VIDAL, Joaquín; CÁCERES PURP, Luis Miguel; RUIZ MUÑOZ, Francisco. 2015: "Eventos marinos de alta energía y cambios traumáticos en los asentamientos costeros del Suroeste de la Península Ibérica". Cuaternario y Geomorfología, 29 (1-2), pp. 57-74.

GÓMEZ MUÑ̃Z, Ma Soledad. 2019: "La cartografía histórica como fuente para el estudio del paisaje cultural marítimo de la Bahía de Cádiz. Una propuesta analítica y metodológica”. Janwa Pana, Vol. 18, No.2, pp 256-276.

GONZALEZ GALLERO, Raul. 2009: "Prospección arqueológica subacuática en aguas de Camposoto, San Fernando". Anuario de Arqueología de Andalucía, en prensa.

GRACIA PRIETO, F. Javier; ALONSO VILLALOBOS, Carlos; ABARCA, Juan Manuel. 2017: "Evolución histórica y geomorfología de las explotaciones salineras en marismas mareales. Ejemplos de la bahía de Cádiz". Cuaternario y Geomorfología, 31(1-2), pp. 45-72.
GUTIÉRREZ MÁS, José Manuel; MORALES, Juan Antonio; DELGADO, Irene. 2015: "Respuesta morfo-sedimentaria de alta energía en el fondo de un canal mareal: caño de Sanctipetri (Bahía de Cádiz, SO España)". Revista de la Sociedad Geológica de España, 28(1), pp 106107.

IZAGUIRRE LACOSTE, Manuel; RIETH, Erith; RODRÍGUEZ MARISCAL, Nuria. 2010: "Investigaciones en el pecio de Camposoto: hacía la identificación del navío francés Fougueux". Revista PH: Boletín del Instituto Andaluz del Patrimonio Histórico, 75, pp. 94-107.

JIMÉNEZ ÁVILA, Javier. 2014: "Bronze Male Deities: Elements for the identification of a Phoenician Group in Mediterranean". En A. ARRUDA (ed.): Fenícios e Púnicos por terra e mar. Actas do VI Congresso Internacional de Estudos Fenícios e Púnicos, pp. 762-771. Lisboa.

LLAVE BARRANCO, Estefanía, HERNÁNDEZ MOLINA, F. Javier; ALONSO VILLALOBOS, Carlos; GALLARDO ABÁRZUZA, Mercedes; VÁZQUEZ GARRIDO, Juan. 1999: "Caracterización y evolución del paleocauce del río Guadalete en la bahía de Cádiz durante el cuaternario terminal". Geogaceta, 26, pp. 43-46.

MÁRQUEZ CARMONA, Lourdes. 2008: "Recuerdos de un timonel: Michel Maffiotte y la rendición de la escuadra de Rosily en la Batalla de la Poza de Santa Isabel (1808)". Trocadero: Revista de historia moderna y contemporánea, 20, pp.33-44.

MÁRQUEZ CARMONA, Lourdes. 2015: “Un comandante del batallón del cuerpo de ingenieros napoleónico en Matagorda (Puerto Real): Garbé y el Sitio de Cádiz". Revista Matagorda, 1, pp. 79-106.

MÁRQUEZ CARMONA, Lourdes. 2020: Recordando un olvido: pontones prisiones en la Bahía de Cádiz. 1808-1810. 2ª ed. Círculo Rojo. Almería. MÁRQUEZ CARMONA, Lourdes; ALONSO VILLALOBOS, Carlos; BENÍTEZ, David. 2016: "El patrimonio cultural marítimo de la Bahía de Cádiz según la visión de un hidrógrafo de Napoleón: El vicealmirante Rosily". Revista de historia de El Puerto, 56, pp. 31-60.

MARTÍN BUENO, Manuel. 2003: "Patrimonio Cultural Sumergido: Investigar y conservar para el futuro". Monte Buciero, 9, pp. 21-62.

MARTÍNEZ SOLARES, Jose Manuel. 2001: "Los efectos en España del terremoto de Lisboa (1 de noviembre de 1755)". Monografia, 19, pp. 
84-95

MÉNANTEAU, Loïc. 2008: "Fisiografía y evolución histórica del entorno de San Fernando (Isla de León, Bahía de Cádiz)". Revista Atlántica-Mediterránea de Prehistoria y Arqueología Social, 10(1), pp. 465-487.

NIVEAU de VILLEDARY Y MARIÑAS, Ana Ma. 2019: "La fundación arcaica de Gadir. La construcción historiográfica de una ciudad ¿real o inventada?" Archivo Español de Arqueologia, 92, pp. 7-41.

OJEDA NOGALES, David. 2017: "Fragmentos de estatuas romanas de bronce procedentes de Cádiz". En S. PANZRAM (ed.): Toletum. Netzwerk zur Erforschung der Iberischen Halbinsel in der Antike, pp. 229-238.

PERDIGONES MORENO, Lorenzo. 1991: "Hallazgos recientes en torno al santuario de Melkart (Cádiz)". II Condresso Internazionale di Studi Fenici e Punici. Vol. Terzo, Roma, pp: 11191132.

PÉREZ FERNÁNDEZ, Enrique. 2017: Cuando el mar se retiró en 1731: Los hallazgos en Sancti Petri. Acceso el 25 de septiembre de 2020. http://www.patrimoniolaisla.com/cuandomar-se-retiro-1731-los-hallazgos-sancti-petri/.

PONZ Y PIQUER, Antonio. 1791: Viaje de España o Cartas en que se da noticia de las cosas más apreciables y dignas de saberse que hay en ella. Madrid.

PRADOS PÉREZ, Eduardo; JIMÉNEZ ÁVILA, Javier, MARTÍN RODRÍGUEZ, Enrique Carlos. 2018: "Una nueva figura de bronce fenicia hallada en Huelva Homenaje a Juana Bedia". En J. M. GARCÍA y L. PÉREZ (coord.): Homenaje a Juana Bedia, pp. 385-407. Consejería de Cultura de la Junta de Andalucía. Huelva.

PRATES, Luciano; BONOMO, Mariano. 2017: "Los ambientes acuáticos en arqueología". Arqueología, 23(3), pp 11-33.

QUINTERO ATAURI, Pelayo. 1906: "Las ruinas del Templo de Hércules en Santipetri". Revista de Archivos, Bibliotecas y Museos. 3 Época. Año X. Tomo XIV. Madrid.

QUINTERO ATAURI, Pelayo. 1926: "Memoria de las excavaciones practicadas en 1925-1926". Revista de Archivos, Bibliotecas y Museos. Junta Superior de Excavaciones y Antigüedades. Madrid. QUINTERO GONZÁLEZ, Jose María. 2000: El arsenal de la Carraca (1717-1736). Ministerio de Defensa. Madrid
RAMOS MUÑOZ, José. 1993: El hábitat prehistórico de El Estanquillo. San Fernando. Fundación Municipal de Cultura, Colección de Temas Isleños, Ayto. de San Fernando.

RODRÍGUEZ DE GUZMÁN, Sandra; GONZÁLEZ-CAMPOS, Yolanda. 2002: "La tutela del Patrimonio Histórico a través de las Cartas Arqueológicas Municipales". Revista PH: Boletín del Instituto Andaluz del Patrimonio Histórico, 38, pp. 79-90.

RODRÍGUEZ MARISCAL, Nuria; RIETH, Erith; IZAGUIRRE LACOSTE, Manuel. 2010: "Investigaciones en el pecio de Camposoto: hacia la identificación del navío francés Fougueux. Revista PH: Boletín del Instituto Andaluz del Patrimonio Histórico, 55, pp. 94-107.

RODRÍGUEZ MARISCAL, Nuria.; ALZAGA, Milagros; RIETH, Erith; IZAGUIRRE LACOSTE, Manuel. 2013: "El Fougueux, análisis del sistema constructivo de un navío de linea de la armada imperial de Napoleón Bonaparte". En X. NIETO, A. RAMÍREZ y P. RECIO (coords.): I Congreso de Arqueologia Náutica y Subacuática Española, pp. 575-59. Madrid.

RODRÍGUEZ OLIVA, Pedro. 1990: "Los bronces romanos de la Bética y la Lusitania". Los bronces romanos en Hispania, pp. 91-102. Ministerio de Cultura. Madrid.

ROMERO DE TORRES, Enrique. 1930: Catálogo Monumental de España: Provincia de Cádiz (1908-1909). Madrid. http://aleph. csic.es/imagenes/mad01/0010 CMTN/ html/001359467 V01F.html\#page/6/mode/2up.

SÁEZ ESPLIGARES, Antonio. 1989: "Informe sobre la recuperación de una figurilla de bronce de época fenicia, encontrada por don Manuel Gorrado". Informe inédito depositado en el Museo Histórico Municipal de San Fernando.

SÁEZ ESPLIGARES, Antonio. 2017: "La antigua Colección Municipal de Arqueología y el nuevo Museo Histórico Municipal de San Fernando". Boletín del Museo Arqueológico Nacional, 35, pp. 81-88.

SÁEZ ROMERO, Antonio, MONTERO FERNÁNDEZ, Ana I.; DÍAZ RODRÍGUEZ, José Juan. 2005: "Nuevos vestigios en el santuario gadirita de Melqart en Sancti Petri (San Fernando, Cádiz)". En J. JIMÉNEZ y S. CELESTINO (coords.): El Período Orientalizante. Actas del III Simposio Internacional de Arqueología de Mérida, Anejos de AEspA, XXXV, pp. 873-878. Madrid. 
SÁEZ ROMERO, Antonio. 2009: "El templo de Melqart de Gadir: hito religioso-económico y marítimo. Consideraciones sobre su relación con la industria conservera". En P. MATEOS, S. CELESTINO, A. PIZZO y T. TORTOSA (eds.): Anejos de AEspA XLV, pp. 115-130. CSIC. Mérida.

SAEZ ROMERO, Antonio M.; SÁEZ ESPLIGARES, Antonio. 2011: "Evidencias de un taller alfarero inédito en el territorium insular de Gades. El alfar de Playa de Camposoto". Boletín Ex Officina Hispana, 3, pp. 26-29

SAEZ ROMERO, Antonio M.; CARRERO RAMÍREZ, Francisco. 2018: "Coto de la Isleta (Chiclana, Cádiz). Nuevos datos y perspectivas sobre el poblamiento romano de la zona sur de la Bahía de Cádiz". SPAL, 27.1, pp. 185-210.

SALAS ÁLVAREZ, Jesus A. 2003: "Los interlocutores y temas tratados en la correspondencia". En J. BELTRÁN y J. LÓPEZ (coord.): El museo cordobés de Pedro Leonardo de Villacevallos: coleccionismo arqueológico en la Andalucía del siglo XVIII, pp. 59-92. Universidad de Málaga. Málaga.

SALAS ÁLVAREZ, Jesus A. 2005: La recuperación del Patrimonio Arqueológico de Andalucía durante la ilustración (1736-1808). Tesis doctoral. Universidad de Sevilla.

SÁNCHEZ-CANTÓN, Francisco Javier. 1943: "La primera colección española de cuadros y estatuas que tuvo catálogo impreso". Boletín de la Real Academia de la Historia, pp. 217-227.

SÁNCHEZ SALAS, Francisco. 2015: "Documentación de archivo para la revisión del trabajo arqueológico. El caso de Punta de Vaca". Revista Atlántica-Mediterránea de Prehistoria y Arqueología Social, 15, pp. 165-179.
SCHULZ, Horst D.; BARRAGÁN, Daniel; BECKER, Veith; HELMS, Marcus; LAGER, Tanja; REITZ, Anja; WILKE, Iris. 2003: "Geschichte des Küstenverlaufs in der Bucht von Cádiz und San Fernando im Holozän". Madrider Mitteilungen, pp. 216-257.

SOLÉ, Anton. 1965: "El anticuario gaditano Pedro Alonso O'Crouley". Archivo Hispalense, 2a época, 136, pp. 151-166.

VALLESPÍN GÓMEZ, Olga. 1977: "Prospecciones Submarinas en Cádiz, 1973". Noticiario Arqueológico Hispánico, Arqueología, 5, pp 291292.

VALLESPÍN GÓMEZ, Olga. 1985: “Carta arqueológica de La Caleta”. VI Congreso Internacional de Arqueología Submarina, Cartagena, 1982, pp 58-73. Ministerio de Educación Cultura y Deporte, Dirección General de Bellas Artes y de Conservación y Restauración de Bienes Culturales.

VALLESPÍN GÓMEZ, Olga. 1986: "The Copper Wreck". The Intenational Journal of Nautical Archaeology and Underwater Exploration, vol 15 , n. 4, pp 305-322. 